\title{
Proposal of a new method in EN1994-1-2 for the fire design of concrete-filled steel tubular columns
}

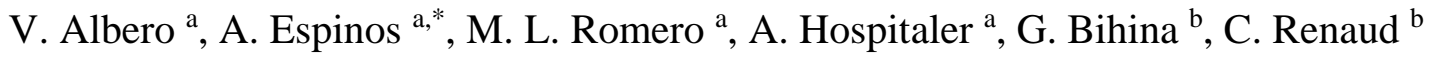 \\ ${ }^{a}$ Instituto de Ciencia y Tecnología del Hormigón (ICITECH), \\ Universitat Politècnica de València, Valencia, Spain \\ ${ }^{b}$ Centre Technique Industriel de la Construction Métallique (CTICM), \\ Saint Aubin, France \\ *Corresponding author.e-mail address: aespinos@mes.upv.es
}

\begin{abstract}
Previous investigations proved the unsafety of the current design guidelines in Annex $\mathrm{H}$ of EN 1994-1-2 for the calculation of the fire resistance of slender concrete-filled steel tubular (CFST) columns. In this paper, a new simplified design method based on the general rules in Clause 4.3.5.1 of EN 1994-1-2 is presented for correcting this inaccuracy. For the development of the method, an extensive parametric study consisting of about 20.500 analysis cases was carried out by using numerical models, which in turn were validated against a wide range of experimental results. The proposed method provides a significant extension over the current EN 1994-1-2 applicability limits, reaching high member slenderness, large eccentricities and being valid for all the commercially available geometries, including elliptical hollow sections. The design proposal is divided into two parts: thermal, where a simplified cross-sectional temperature field can be obtained based on equivalent temperatures for the composite section constituents, and mechanical, where a full method for evaluating the ultimate buckling load in the fire situation is given. The proposed method is valid for axially and eccentrically loaded columns, accounting for eccentricities on both minor and major axis and reaching large eccentricities of $\mathrm{e} / \mathrm{D}=1$. Finally, it is proved that the proposed method provides safe predictions as compared to experimental results and meets the CEN/TC250/SC4 accuracy criteria.
\end{abstract}


Albero V, Espinos A, Romero ML, Hospitaler A, Bihina G, Renaud C. Proposal of a new method in EN1994-1-2 for the fire design of concrete-filled steel tubular columns. Eng. Struct. 2016; 128:237-55. doi: 10.1016/j.engstruct.2016.09.037

Keywords: Concrete-filled tubular columns, fire resistance, simplified design methods, numerical analysis, parametric studies, Eurocode 4 


\section{NOTATION}

$A_{i, \theta} \quad$ cross-sectional area of the part $i$ of the composite section at the temperature $\theta$
$A_{m} / \mathrm{V}$ section factor
width of the square section or smaller outer dimension of an elliptical or rectangular section

CFST Concrete-Filled Steel Tube

CHS Circular Hollow Section

$D$

outer diameter of the circular section

$e$

load eccentricity

$E_{i, \theta}$

modulus of elasticity of the $i$ material at the temperature $\theta$

$(E I)_{f i, e f f}$

effective flexural stiffness in the fire situation

EHS

Elliptical Hollow Section

EC4

Eurocode 4

$f_{c}$

compressive cylinder strength of concrete at room temperature

$f_{y}$

yield strength of structural steel at room temperature

$f_{s}$

yield strength of reinforcing steel at room temperature

$H$

Larger outer dimension of an elliptical or rectangular section

$I_{i, \theta}$ second moment of area of the part $i$ of the cross-section at the temperature $\theta$

$k_{i, \theta}$ reduction factor for a material property at elevated temperature

$l_{\theta}$ buckling length in the fire situation

$N_{f i, \mathrm{cr}} \quad$ elastic critical load in the fire situation

$N_{f i, \mathrm{pl}, R d} \quad$ plastic fire design resistance of the cross-section to axial compression

$N_{f i, R d} \quad$ design axial buckling load in the fire situation

$N_{f i, R d, \delta} \quad$ design buckling load in the fire situation in case of eccentric load

$N_{R d} \quad$ design axial buckling load at room temperature 
$N_{R d, \delta} \quad$ design buckling load at room temperature in case of eccentric load

$R$ standard fire resistance time (minutes)

RHS Rectangular Hollow Section

SHS Square Hollow Section

$t$

steel tube wall thickness

$\theta$

temperature

$\bar{\lambda}$

relative slenderness at room temperature

$\bar{\lambda}_{\theta}$

relative slenderness in the fire situation

$\xi$

relative error

$\varphi_{i, \theta}$

reduction coefficient to make allowance for the effect of thermal stresses

$\chi$

resistance reduction factor according to the European buckling curves 


\section{INTRODUCTION}

Concrete-filled steel tubular (CFST) columns are among the most commonly used composite members in modern buildings due to their high stiffness, ductility and in particular excellent fire performance. However, the current design guidelines for the fire resistance of CFST columns in Annex H of EN 1994-1-2 [1] have been found unsafe for relative member slenderness over 0.5, which is a frequent situation for columns in car-parks, high-rise, commercial, or industrial buildings. Previous works from Romero et al. [2] for circular CFST columns pointed out that only a reduced fire resistance (FR) can be obtained in slender columns, where the FR was generally lower than 30 minutes, while the current design rules in EC4 predict a higher FR, thus resulting unsafe. This work agreed with previous results from Renaud et al. [3] and Leskela et al. [4] and led to the approval of an amendment by the committee CEN/TC 250/SC4 which limits the relative slenderness at ambient temperature to 0.5 in the application of Annex H of EC4, which is specific for CFST columns exposed to fire. In consequence, this committee created an Ad-hoc group to redefine the current Annex H.

The interest in the use of simple design rules for concrete-filled steel tubular columns has grown in the last decades, due to the increased usage of this structural typology [5]. Nevertheless, only a limited number of methods are available to designers for evaluating the fire resistance of this type of composite columns, which are a result of the numerical and experimental investigations carried out by the main research groups working in this field (Han et al. [6, 7], Kodur et al. [8-10], Park et al. [11, 12].

Therefore, apart from EC4, other methods can be found in the literature for calculating the fire resistance of CFST columns. Kodur $[8,10]$ proposed a simplified equation developed through the results of a parametric studies supported by an experimental program. This approach is used in the United States and Canada after having been incorporated into several building codes. The applicability of the equation proposed by Kodur is limited to 
$l_{\theta}=2000-4000 \mathrm{~mm}$, therefore the method cannot be applied to columns with high slenderness. Additionally, Han, Zhao and co-workers proposed a formulation which was incorporated to the Chinese code DBJ13-51-2003 [13] limited for circular CFST columns infilled with plain concrete. The formulation of this method can be found in [6]. Finally, amongst the simplified methods for the calculation of the fire resistance of CFST columns existing worldwide, the Japanese approach published in the design manual of the Association of New Urban Housing Technology (ANUHT) [14] should be mentioned.

Turning to EC4, its simplified method for calculating the fire resistance of CFST columns has been proved to be unsafe and besides presents some limitations. The application of the general principles in Clause 4.3.5.1, instead of Annex H, may be an alternative to the referred Annex, although in practice this is not possible for this type of columns, as the reduction coefficients to account for the effect of the thermal stresses are not given for concrete-filled hollow sections. In this situation, the common procedure in practice is to assume them equal to unity [15] or obtain them from Annex G, which is specific for partially encased sections. Certainly, this problem can be solved using the French National Annex to EN 1994-1-2 [1] where specific values for the flexural stiffness reduction coefficients have been included. Nevertheless, this option provides too conservative results [16]. Alternatively, the specific method in Annex H for CFST columns can be used, although as it has been highlighted, the method results unsafe for slender columns and its applicability has been limited to a maximum slenderness of 0.5. In Annex $\mathrm{H}$, the buckling length is also limited to $l_{\theta} \leq 4.5 \mathrm{~m}$ and standard fire resistance times under 120 minutes, which is insufficient for many practical applications.

Another limitation of the method is the shape of the sections. It is limited to circular and square hollow sections while in practice, new shapes such as elliptical hollow sections have become increasingly common because of their architectural aesthetics. An important drawback of the current methods in EC4 is the need for the designer of obtaining the cross-sectional 
temperature field as a preliminary step, for the subsequent calculation of the design axial buckling load, while the code does not provide any simplified method for that purpose. This makes designers feel unwilling to use these methods, and therefore a simplified way for obtaining the cross-sectional temperature field, like that proposed by Ibañez et al. [17] for CHS columns, would be of interest for practitioners and ultimately for promoting the use of this type of composite sections. Other way to deal with this drawback, different from the one exposed in this work, was developed by the authors through the concept of an equivalent concrete core cross-section at room temperature [17].

In order to solve the exposed shortcomings, the European Union decided to support a research project entitled "Fire Resistance of Innovative and Slender Concrete Filled Tubular Composite Columns" (FRISCC), through a financial grant of the Research Programme of the Research Fund for Coal and Steel.

This paper presents a simplified design method, developed under the aforementioned project, which extends the current EC4 method limitations and corrects its inaccuracy. The proposed method has been developed through the results of an extended parametric study carried out using numerical models which were in turn supported by validation against experimental results. It includes innovative cross-sections, such as elliptical hollow sections. The proposed simplified method is developed to deal with unprotected CFST columns under ISO standard fire condition. A new set of reduction coefficients are developed to account for the effect of thermal stresses in CFST columns, in order to propose a simple calculation model which follows the general principles in Clause 4.3.5.1 of EN 1994-1-2 [1]. Additionally, in order to make easier for designers the calculation of the cross-sectional temperature field, a simplistic proposal is presented, based on the equivalent temperature concept. Finally, a method with coefficients to cover the design of CFST columns with large eccentricities is proposed.

\section{REVIEW OF EXISTING DESIGN GUIDANCE FROM EUROCODE 4}


In the current version of EN 1994-1-2 [1] (EC4), simplified design rules are available for calculating the fire resistance of CFST columns, specifically Clause 4.3.5.1 describes a general method for evaluating the ultimate load of composite columns in the fire situation based on the elastic buckling theory. Besides, Annex $\mathrm{H}$ (informative) includes a specific method for fire design that is not based on the general principles of Section 4.3.5.1, for unprotected concrete filled hollow section columns. Through this method, the ultimate buckling load can be obtained from the following equilibrium equation:

$$
N_{f i, R d}(\varepsilon)=N_{f i, c r}(\varepsilon)=N_{f i, p l, R d}(\varepsilon)
$$

where the ultimate buckling load in fire $N_{f i, R d}(\varepsilon)$ is obtained through an incremental procedure, when the equilibrium between the Euler buckling load $N_{f i, r}(\varepsilon)$ and the plastic resistance to axial compression $N_{f i, p l, R d}(\varepsilon)$ at elevated temperatures is found.

The procedure is based on increasing the strain in steps until $N_{f i, c r}(\varepsilon)$ and $N_{f i, p l, R d}(\varepsilon)$ are equal, obtaining for each increment the stress distribution using the material properties at elevated temperatures for the fire exposure time evaluated. It should be mentioned that the Euler buckling load in this method is not the same as in general principle of Clause 4.3.5.1 but base on the tangent stiffness evaluation of the elastic modulus from stress-strain properties of the column materials. This also forms a trap of misinterpreting the method and may led to situation where the results of analyses are not applied, as they should.

Numerical investigations have been conducted to date, revealing important shortcomings of the Annex $\mathrm{H}$ method [3, 18, 19]. It was found out that this method produces unsafe predictions for slender columns. These findings have led to an inclusion of an amendment to the existing Annex $\mathrm{H}$ by the committee CEN/TC 250/SC4, which states that the relative slenderness of the columns should be limited to $\bar{\lambda} \leq 0.5$ for the usage of the method. 
Given this situation, the general calculation method for composite columns in Clause 4.3.5.1 of EN 1994-1-2 [1] can be used instead. In this method, the design value of the resistance of composite columns in axial compression exposed to fire is calculated as:

$$
N_{f i, R d}=\chi N_{f i, p l, R d}
$$

where $\chi$ is the reduction coefficient from buckling curve "c" provided by Clause 6.3.1.2 of EN 1993-1-1 [20] but obtained for the value of the relative slenderness at elevated temperature $\left(\bar{\lambda}_{\theta}\right)$ and $N_{f i, p l, R d}$ is the plastic resistance of the composite cross-section, defined by:

$$
N_{f i, p l, R d}=\sum_{j}\left(A_{a, \theta} f_{a y, \theta}\right) / \gamma_{M, f i, a}+\sum_{k}\left(A_{\mathrm{s}, \theta} f_{s y, \theta}\right) / \gamma_{M, f i, \mathrm{~s}}+\sum_{m}\left(A_{\mathrm{c}, \theta} f_{c y, \theta}\right) / \gamma_{M, f i, \mathrm{c}}
$$

where $A_{i, \theta}$ is the area of each cross-section element to which a certain temperature $\theta$ is attributed and subscripts "c", "s", and "a" refer to concrete core, reinforcing bars and steel tube, respectively. The partial factor for the materials in the fire situation are denoted as $\gamma_{M, f i, i}$

The relative slenderness of a CFST column at elevated temperatures, needed to obtain the buckling reduction coefficient from the buckling curve "c", is given by:

$$
\bar{\lambda}_{\theta}=\sqrt{N_{f i, p l, R} / N_{f i, c r}}
$$

where $N_{f i, p l, R}$ is equal to $N_{f i, p l, R d}$ when the value of the partial factor for the materials are taken as 1.0 and $N_{f i, c r}$ is the Euler buckling load in the fire situation, defined as follows:

$$
N_{f i, c r}=\pi^{2}(E I)_{f i, e f f} / l_{\theta}^{2}
$$

The effective length of the columns at certain temperature is denoted as $l_{\theta}$ and the effective flexural stiffness of the column at elevated temperature can be calculated through:

$$
(E I)_{f i, e f f}=\sum_{j}\left(\varphi_{a, \theta} E_{a, \theta} I_{a, \theta}\right)+\sum_{k}\left(\varphi_{\mathrm{s}, \theta} E_{\mathrm{s}, \theta} I_{s, \theta}\right)+\sum_{m}\left(\varphi_{\mathrm{c}, \theta} E_{\mathrm{c}, \mathrm{sec}, \theta} I_{\mathrm{c}, \theta}\right)
$$


where $I_{\mathrm{i}, \theta}$ are the second moment of area for each cross-section element to which a certain temperature $\theta$ is attributed, $E_{\mathrm{i}, \theta}$ are the slope of the elastic range for each cross-section element material at each temperature and finally $\varphi_{\mathrm{i}, \theta}$ are the reduction coefficients depending on the effect of thermal stresses. For partially encased steel sections these coefficients are provided by Annex G of EC4. However, they still have to be established for CFST sections, only studies from CTICM $[3,18]$ can be found in the literature on the suitable values of these coefficients added to the EN 1994-1-2 French National Annex-, developed for CHS and SHS columns, or the recommendations from previous work of the authors of this paper [16].

Regarding eccentric loads, two approaches are currently available in EC4 for composite columns. The first one is given in Clause H.4 from Annex H for CFST columns, which provides an equivalent axial load accounting for eccentricity:

$$
N_{e q u}=N_{f i, S d} /\left(\varphi_{s} \cdot \varphi_{\delta}\right)
$$

where $N_{f i, S d}$ is the eccentric load applied and $\varphi_{s}, \varphi_{\delta}$ are coefficients defined in Annex $\mathrm{H}$ of EC4 depending on the percentage of reinforcement, eccentricity $(\delta$ ) and member slenderness $\left(l_{\theta} / D\right)$ or $\left(l_{\theta} / \mathrm{B}\right)$. The resulting equivalent load $N_{e q u}$ may be used in connection with the design axial buckling load at elevated temperatures calculated from Clause H.3, as explained before.

Secondly, Clause G.7 from Annex G provides a method for partially encased steel section columns valid when the application point of the eccentric load remains inside the composite cross-section, which assumes that the same relation exists between concentric and eccentric design axial buckling load at room temperature and in the fire situation:

$$
N_{f i, R d, \delta}=N_{f i, R d}\left(N_{R d, \delta} / N_{R d}\right)
$$


where $N_{R d}$ and $N_{R d, \delta}$ represent the concentric and eccentric axial buckling load, respectively, calculated according to EN 1994-1-1 [21], for normal temperature design.

\section{NUMERICAL MODELS AND PARAMETRIC STUDIES}

\subsection{Description of the numerical models}

In this work, two numerical models were developed to simulate the fire behaviour of concrete filled tubes. Specifically, three-dimensional and two-dimensional finite element models were developed at Universitat Politècnica de València (UPV) and Centre Technique Industriel de la Construction Métallique (CTICM), respectively. These models are described hereafter.

The three-dimensional numerical model from UPV was developed by means of the general purpose nonlinear finite element analysis package ABAQUS [22].This model, which takes into account a sequentially coupled thermal-stress analysis, was deeply described in previous papers by the authors [23]. The simulations were performed by first conducting a pure heat transfer analysis for obtaining the temperature field, and afterwards a stress/deformation analysis for calculating the structural response. The main heat transfer parameters were fixed using the values recommended by EN 1991-1-2 [24]. Besides, in order to take into account the thermal resistance at the boundary surface between the steel tube and the concrete core, a constant value of $200 \mathrm{~W} / \mathrm{m}^{2} \mathrm{~K}$ was used for the gap conductance at that boundary surface. Moreover, an initial geometric imperfection of the columns was considered, which was obtained as the first buckling mode shape of a hinged column multiplied by an amplification factor of $\mathrm{L} / 1000$.

The model was meshed with three-dimensional eight-noded solid elements for both the steel tube and the concrete core, and two-noded solid elements for the reinforcing bars. The loading plate was modelled as a discrete rigid part with all nodes coupled to a reference point. 
This rigid plate was meshed using two-dimensional four-noded shell elements. Based on the results of a mesh sensitivity study [23], a maximum finite element size of $2 \mathrm{~cm}$ was used. Fig. 1 shows the finite element mesh for a CFST specimen.

It can be seen in Fig. 1 that, due to symmetry of both the geometry and the boundary conditions, only a quarter of the columns needs to be modelled.

The temperature dependent thermal and mechanical properties of the materials were accounted for in the numerical model. Furthermore, the values of the parameters given in the Eurocodes were used, so as to obtain a model which was completely based on the European standards. Therefore, the thermal properties for concrete and steel at elevated temperatures were obtained from Clause 3.3 in EN 1994-1-2 [1] for steel-concrete composite structural elements. It should be pointed out that the upper limit of the concrete thermal conductivity was used, as recommended in Note 2, Clause 3.3.2(9). Also a 4\% concrete moisture content was assumed in the model, as given in Clause 3.3.2(7) and the latent heat of water vaporisation was taken into account through a peak value in the specific heat capacity formulation between 100 and $200^{\circ} \mathrm{C}$, as per Clause 3.3.2(8).

For characterizing the mechanical behaviour of the materials, a multi-axial model needed to be defined. ABAQUS provides several material models built from uniaxial material behaviour. For steel, an isotropic elastic-plastic model, with von Mises yield criterion, was used. In turn, the Concrete Damage Plasticity (CDP) model was used for modelling the mechanical behaviour of concrete as previously done by other authors [25], which allows for a detailed definition of tensile and compressive behaviour of the material. The input parameters used for the CDP model were the following: dilation angle of $15^{\circ}$, eccentricity of 0.1 , initial equibiaxial to initial uniaxial compressive yield stress ratio of 1.16 and the parameter related to the shape of the yield surface in the deviatoric plane equal to $2 / 3$. No variation of these parameters in terms of temperature was considered. 
The constitutive models selected for representing the uniaxial behaviour of steel and concrete at elevated temperatures, and their reduction factors were those given by EN 1993-12 [26] and EN 1992-1-2 [27], respectively.

In turn, the two-dimensional model developed at CTICM is a fibre-based model which allows simulating with a significant reduction of computational time the structural behaviour of steel-concrete composite columns subjected to any fire conditions. A detailed presentation of the finite element formulation and the solution algorithms can be found in several papers [28], [29], [30].

In this model, any composite column with hollow steel section whose flexural bending occurs in a symmetrical plane is represented by new two-noded beam-column elements using the updated Lagrangian formulation. As illustrated in Fig. 2, the proposed beam-column element consists of two traditional beam-column elements complying with the Euler-Bernoulli theory (for the hollow steel section and the concrete core) combined with a specific link element of zero thickness allowing full, partial or zero shear connection (owing to mechanical bond) at the steel-concrete interface. After the assemblage of these three finite sub-elements, the proposed beam-column element has four degrees of freedom at each node. Apart from the conventional two translational and single rotational degrees of freedom, it has an extra degree of freedom which represents the relative displacement between the steel and the concrete parts of composite columns.

Because of the changes in material properties and the large deflections experienced under severe conditions of heat exposure, both geometric and material non-linearities are taken into account. The cross-section of the above-mentioned traditional beam-column element is divided into small fibres which can be triangular or quadrangular, and each fibre may have different material, temperature and mechanical properties. For a given temperature distribution in a cross section, the assumption is made that the total strain of every fibre (steel and concrete) is equal 
to the sum of four independent terms, related to the stress exerted on the fibre at the relevant temperature, to thermal elongation, to residual stress and to creep, respectively. In principle, any stress-strain relationship as a function of the temperature can be introduced in the finite element model. The material properties recommended in EN 1994-1-2 are, however generally adopted to be consistent with the code [1], considering that creep strains of steel and concrete are implicitly included in their stress-strain relationships at elevated temperature.

The temperature distribution is obtained separately from a two-dimensional heat transfer analysis. The thermal calculation is conducted using FEA code Cast3M, considering usually only a quarter of the column cross-section owing to double symmetry.

\subsection{Validation of the numerical models}

The previously described numerical models were validated against the experimental results from an extensive fire testing campaign carried out by the authors within the project FRISCC [31], [32] obtaining a successful fitting, see Table 1. Although the 3D model was already validated in previous works [23], a new validation was needed in order to check its accurate behaviour for all sections shapes (CHS, SHS, RHS and EHS). Moreover, the 2D model was also validated against the same experimental results, verifying that both models were consistent and reached a good agreement.

Table 1 shows the relative error of the predictions $\xi$ in terms of fire resistance time, defined as follows:

$$
\xi=\frac{t_{\text {TEST }}}{t_{N U M}}
$$

where values greater than 1 mean safe predictions and values lower than 1 mean unsafe predictions. It can be seen that through both numerical models, relative errors close to unity were obtained, showing their accuracy. 
Besides, in Fig. 3 a comparison between the experimental and numerical axial displacement results of four specimens, one of each section shape, are shown, obtaining an accurate fitting between both models and the experiment.

\subsection{Parametric studies}

Once the previously described numerical models were validated, they were used for conducting a parametric study. An extensive simulation programme was designed in this parametric study, in order to investigate the behaviour of CFST columns at elevated temperatures. After having proved that the response of the two-dimensional model was close to that of the three-dimensional model, the first one (2D) was used to perform the numerical simulations, since it allowed for a significant reduction of the computational cost of this study. In order to make sure that both models provided the same response, some checkpoints were performed randomly, and their results compared. These results are not included here for sake of simplicity.

The parameters studied were the outer diameter $(D)$ or larger and smaller outer dimension $(H-B)$ in the case of rectangular and elliptical columns respectively, the wall thickness of the steel tube $(t)$, the relative slenderness of the columns at room temperature $(\bar{\lambda})$, the percentage of reinforcement $(\rho)$, the concrete cover $\left(u_{s}\right)$, the load level $(\mu)$ and the relative eccentricity $(e / D$, e/Hor $e / B)$.

A comprehensive study was carried out, in order to define the cases to analyse in the parametric study. Based on a previous evaluation of the commercially available section shapes and their usage in construction, the cross-section dimensions and ranges of variation of the parameters were decided. Table 2 shows the range of variation of the parameters for all section shapes, resulting a total of 4400 circular, 4400 square, 8136 rectangular and 3600 elliptical columns, which means a total amount of 20536 numerical simulations combining the different parameters. Besides 2000 checkpoints were performed with the 3D model approximately. It 
should be pointed out that some specimens were designed without reinforcement given the minimum rebar spacing requirements from EN 1992-1-1 [33].

The case specimens for the parametric studies were designed to meet the criteria of nonslender sections $\left(D / t \leq 90 \varepsilon^{2}\right)$, with a steel contribution ratio between $0.2 \leq \delta \leq 0.9$. Regarding the reinforcement, the arrangements shown in Fig. 4 were considered, which cover widely the practical usage. The rest of the input parameters adopted were as follows: $4 \%$ moisture content, pinned-pinned boundary conditions, $355 \mathrm{MPa}$ steel tube yield strength, $30 \mathrm{MPa}$ concrete compressive strength and $500 \mathrm{MPa}$ reinforcing bars yield strength.

A $4 \%$ moisture content is assumed in the simulations, as given in Clause 3.3.2(7). The latent heat of water vaporisation is taken into account through a peak value in the specific heat formulation between 100 and $200^{\circ} \mathrm{C}$, as per Clause 3.3.2(8).

\section{RESULTS AND DISCUSSION OF EUROCODE 4 PART 1.2}

The numerical buckling load at elevated temperature was computed from the results of all calculations performed in the parametric study. It was defined as the axial buckling load obtained from numerical simulation divided by the cross-section plastic resistance in fire situation $\left(\chi^{N U M}=N_{f i, R d}^{N U M} / N_{f i, p l, R d}\right)$ and is plotted against the relative slenderness at elevated temperatures $\left(\bar{\lambda}_{\theta}=\sqrt{N_{f i, p l, R d} / N_{f i, c r}}\right)$ in Fig. 5. This figure only shows the results for axially loaded columns, 3000 specimens approximately from all sections shapes (CHS, SHS, RHS and EHS), superimposed with buckling curve "c", which is used in Clause 4.3.5.1(2) of EN 19941-2 [1] for the fire design of composite columns. It can be observed that most cases lie below buckling curve "c", which suggest that the general method for axially loaded composite columns of EC4 lies on the unsafe side, unless appropriate reduction factors smaller than unity are employed. It should be pointed out that the eccentrically loaded cases were not plotted in 
this figure since their comparison against any buckling curve is not useful and does not provide relevant information, as these curves are defined for axially loaded columns.

In order to compare all the results, axially and eccentrically loaded, against the existing design methods, the buckling load for all specimens performed in the parametric study was calculated by means of the two approaches currently available in Eurocode 4, described in Section 2. Specifically, the general method for composite columns in Clause 4.3.5.1 of EN 1994-1-2 [1] with flexural stiffness reduction coefficients equal to unity (EC4(1)) and the simple calculation model in Annex H of EN 1994-1-2 [1] (EC4(H)) were applied.

Fig. 6 shows the comparison between the simple calculation methods - EC4(1), Fig. 6a and EC4(H), Fig. 6b - and the numerical results for axially loaded specimens. It can be observed that, in both simplified methods, most cases lie on the unsafe side reaching deviations higher than $95 \%$ over the reference numerical value, which reflects that they are highly unsafe. Besides, Fig. 6c and 6d plot the relative error of the predictions $\xi$ against the relative slenderness of the columns at room temperature $\bar{\lambda}$, defined as follows:

$$
\xi=\frac{\chi^{N U M}}{\chi^{P R E D}}
$$

This error definition provides values higher than unity when the predictions are safe ( $\left.\chi^{N U M}>\chi^{\text {PRED }}\right)$ and lower than unity when the predictions are unsafe $\left(\chi^{\text {NUM }}<\chi^{\text {PRED }}\right)$. It can be observed that the dispersion of the relative error is higher for $\mathrm{EC} 4(\mathrm{H})$ and both methods have a mean value lower than unity, meaning unsafe predictions. Fig. 6c shows that EC4(1) method provides more accurate predictions for relative slenderness values over 1.5.

In addition, for eccentrically loaded columns, the comparison was carried out also against two different approaches taken from EN 1994-1-2 [1],which were also described in Section 2. Firstly, the general method for composite columns from Clause 4.3.5.1 of combined with the correction to account for eccentricity provided by Annex G for partially encased steel sections 
was used. This proposal assumes that the same relation exists between the concentric and eccentric design axial buckling load at room temperature and in the fire situation, and was defined in this work as EC4(1). $\left(N_{R d, \delta} / N_{R d}\right)$, Fig. 7a.

$$
N_{f i, R d, \delta}=N_{f i, R d} \cdot\left(\mathrm{N}_{R d, \delta} / N_{R d}\right)
$$

Secondly, the proposal provided by Annex H of EN 1994-1-2 [1] was assessed, using the coefficients $\varphi_{s}, \varphi_{\delta}$ from Section H.4, Fig. $7 \mathrm{~b}$.

$$
N_{f i, R d, \delta}=N_{f i, R d} \cdot \varphi_{s} \cdot \varphi_{\delta}
$$

The numerical results, compared with the described methods, are displayed in Fig. 7, showing unsafe predictions under both approaches. Additionally, it can be seen that the $\mathrm{EC} 4(\mathrm{H}) \cdot \varphi_{\mathrm{s}} \varphi_{\delta}$ method provides more scattered predictions. It should be noted that some of the predictions through this method result too conservative because of the low value of the coefficient $\varphi_{s}$ for unreinforced specimens (0.4 in Figure H.1 from Annex H). These analysis cases can clearly be distinguished in Fig. 7, grouped below the $-30 \%$ error line.

\section{DEVELOPMENT OF A SIMPLIFIED DESIGN METHOD FOR CFST COLUMNS}

\subsection{Simplified cross-sectional temperature field}

In order to be able to calculate the buckling load in the fire situation of a CFST column using the simple calculation models from EN 1994-1-2 [1], the cross-sectional temperature field at elevated temperature is previously required. However, Eurocode 4 does not provide any simplified method to obtain this temperature field. Therefore, in order to help designers in this task, a simple method to calculate the temperature field within the cross-section of a CFST column is proposed here.

In contrast with previous studies from the authors [16], [34], which provide a simplified method to obtain the temperature field in circular and elliptical CFST columns, the method 
proposed here is extended to square and rectangular sections up to 240 minutes of fire exposure time for all section shapes. The main advantage of this novel method is that it is valid for CHS, SHS, RHS and EHS columns and fire exposure times ranging from 30 to 240 minutes.

In order to simplify the method, a single equivalent temperature is provided for each part of the cross-section: an equivalent temperature for the whole concrete core $\left(\theta_{c, e q}\right)$, another one for the steel tube $\left(\theta_{a, e q}\right)$ and finally one for the reinforcement $\left(\theta_{s, e q}\right)$. This approach is already used in Annex G of EN 1994-1-2 [1] for composite columns with partially encased steel sections, being its main benefit that designer can evaluate the fire resistance of the column by using a single strength and stiffness value for each component of the composite cross-section corresponding to its equivalent temperature. Therefore, the cross-sectional plastic resistance and effective flexural stiffness of the column in the fire situation may be evaluated with the use of only three equivalent temperatures as:

$$
\begin{aligned}
& N_{f i, p l, R d}=A_{a} f_{y}\left(\theta_{a, e q}\right)+A_{c} f_{c}\left(\theta_{\mathrm{c}, e q}\right)+A_{s} f_{s}\left(\theta_{\mathrm{s}, e q}\right) \\
& (E I)_{f i, e f f}=\varphi_{a, \theta} E_{a}\left(\theta_{a, e q}\right) I_{a}+\varphi_{\mathrm{c}, \theta} E_{c}\left(\theta_{\mathrm{c}, e q}\right) I_{c}+\varphi_{\mathrm{s}, \theta} E_{s}\left(\theta_{\mathrm{s}, e q}\right) I_{s}
\end{aligned}
$$

The same calculation procedure proposed by Espinos et al. [16] to obtain the equivalent temperature for each cross-section part, extended to other section shapes and fire exposure times, is followed hereafter.

\section{Calculation of the equivalent temperature for the concrete core}

By using the realistic cross-sectional temperature field obtained from the previously described parametric studies results, the equivalent temperature representing the whole concrete core can be found through two different approaches, being $A_{c, \theta, i}$ the area of a particular layer from the numerical model at the temperature $\theta$ and $I_{c, \theta, i}$ the second moment of area of the same layer:

a) Plastic resistance approach 
The plastic resistance to axial compression of the concrete core at elevated temperature is equal to:

$$
N_{f i, p l, R d, c}=\sum_{i=1}^{n}\left(A_{c, \theta, i} f_{c, \theta, i}\right)=\sum_{i=1}^{n}\left(A_{c, \theta, i} k_{c, \theta, i} f_{c}\right)=f_{c} \sum_{i=1}^{n}\left(A_{c, \theta, i} k_{c, \theta, i}\right)
$$

A single equivalent temperature which provides the same plastic resistance, $\theta_{c, e q 1}$, can be deduced as follows:

$$
N_{f i, p l, R d, c}=f_{c} \sum_{i=1}^{n}\left(A_{c, \theta, i} k_{c, \theta, i}\right)=k_{c, \theta}\left(\theta_{c, e q 1}\right) f_{c} A_{c} \rightarrow k_{c, \theta}\left(\theta_{c, e q 1}\right)=\frac{\sum_{i=1}^{n}\left(A_{c, \theta, i} k_{c, \theta, i}\right)}{A_{c}}
$$

From eq. (16), the reduction factor to be applied to the whole concrete core can be obtained, and through Table 3.3 in EN 1994-1-2 [1] the equivalent temperature can be deduced by linear interpolation.

b) Flexural stiffness approach

The flexural stiffness of the concrete core at elevated temperature is equal to:

$$
(E I)_{f i, c}=\sum_{i=1}^{n}\left(E_{c, \sec , \theta, i} I_{c, \theta, i}\right)=\sum_{i=1}^{n}\left(\frac{f_{c, \theta, i}}{\varepsilon_{c u, \theta, i}} I_{c, \theta, i}\right)=\frac{f_{c}}{\varepsilon_{c u}} \sum_{i=1}^{n}\left(\frac{k_{c, \theta, i}}{\frac{\varepsilon_{c u, \theta, i}}{\varepsilon_{c u}}} I_{c, \theta, i}\right)=E_{c, s e c} \sum_{i=1}^{n}\left(k_{E c, \theta, i} I_{c, \theta, i}\right)
$$

where $k_{E c, \theta, i}=k_{c, \theta, i} \varepsilon_{c u} / \varepsilon_{c u, \theta, i}$

As in the previous approach, a single equivalent temperature which provides the same flexural stiffness, $\theta_{c, e q 2}$, can be obtained through an equivalent reduction factor by linear interpolation from Table 3.3 in EN 1994-1-2 [1].

$$
(E I)_{f i, c}=E_{c, \sec } \sum_{i=1}^{n}\left(k_{E c, \theta, i} I_{c, \theta, i}\right)=k_{E c, \theta}\left(\theta_{c, e q 2}\right) E_{c, \sec } I_{c} \rightarrow k_{E c, \theta}\left(\theta_{c, e q 2}\right)=\frac{\sum_{i=1}^{n}\left(k_{E c, \theta, i} I_{c, \theta, i}\right)}{I_{c}}
$$

This procedure was carried out for all cross-sections analysed in the parametric studies by using the results from the numerical model, obtaining $\theta_{c, e q 1}$ and $\theta_{c, e q 2}$ for all specimens. These 
temperatures were obtained for intervals of 15 minutes, from 30 to 240 minutes, covering the main standard fire periods. Conservatively, the equivalent temperature of the concrete core was defined as the maximum of the temperatures obtained through the two approaches described (frequently the two temperature values do not differ much from each other):

$$
\theta_{c, e q}=\max \left\{\theta_{c, e q 1}, \theta_{c, e q 2}\right\}
$$

The evolution of the equivalent temperature of the concrete core is plotted in Fig. 8a showing, as was expected, that the equivalent temperature increases as the fire exposure time increases. Besides, similarly to previous works [16], it was observed that the concrete core equivalent temperature is also affected by the section factor of the column $\left(A_{m} / V\right)$ reaching higher values for the columns with higher section factor values, which expose a higher surface to the fire for the same volume. By using the section factor concept, a generalized approach was developed, which can be used for all section shapes (CHS, SHS, RHS and EHS). A nonlinear regression analysis was applied to all the column specimens from the parametric studies, where the equivalent temperature is a function of the fire exposure time and section factor:

$$
\begin{aligned}
& \theta_{c, e q}=81.801-5.046 R+0.003 R^{2}-15.07 A_{m} / V+0.331\left(A_{m} / V\right)^{2} \\
& -0.875 R \cdot A_{m} / V+7.428 R^{0.842} \cdot\left(A_{m} / V\right)^{0.714}
\end{aligned}
$$

With the aid of this regression equation, a selection chart was built up to help practitioners obtaining the equivalent temperature of the concrete core (Table 3).

In this chart, temperatures for the standard fire exposure times are provided, which can also be interpolated for intermediate values of the section factor or fire exposure time. Through the parametric studies results, the predictions of the proposed selection chart were assessed, showing accurate results with 0.979 average error and $4.39 \%$ standard deviation, see Fig. 9a.

\section{Calculation of the equivalent temperature for the steel tube}

In contrast with the strong temperature gradient which develops through the concrete core, in the case of the steel tube, the temperature remains almost uniform through the wall 
thickness. This study showed a strong relation of the steel tube equivalent temperature with the fire exposure time and also with the section factor $\left(A_{m} / V\right)$, although this dependency was weaker than for concrete core equivalent temperature. Like previously, through the section factor of the column, the method was generalized for all CFST shapes, extending the previous works from the authors developed only for CHS and EHS columns [16], [34].

The evolution of the equivalent temperature for the steel tube, calculated using the data of all specimens from the parametric studies, is shown in Fig. 8b, from where a non-linear regression equation was obtained:

$$
\theta_{\mathrm{a}, e q}=-824.667-5.579 R+0.007 R^{2}-0.009 R \cdot A_{m} / V+645.076 R^{0.269} \cdot\left(A_{m} / V\right)^{0.017}
$$

A selection chart was also built up to help designers obtaining the equivalent temperature of the steel tube, this chart is added in Table 3. The chart can be used to interpolate intermediate values. Through the results from the parametric studies, the accuracy of the selection chart was assessed, obtaining an average error of 1.005 and $1.56 \%$ standard deviation, see Fig. 9b.

\section{Calculation of the equivalent temperature for the reinforcement}

In the case of the reinforcing bars, the equivalent temperature can also be obtained from the parametric studies results. Previous works from the authors [34] presented a simplified model to obtain the equivalent temperature for CHS columns, although only for a specific concrete cover value $\left(\mathrm{u}_{\mathrm{s}}=30 \mathrm{~mm}\right)$. In contrast, this parametric study was designed to provide an extensive result which covers the practical range, containing specimens with different concrete cover values. Besides, the work was extended to other section shapes: SHS, RHS and EHS.

Studying the cross-sectional temperature field, a strong relation of the temperature of the reinforcing bars with $R / u_{s}{ }^{2}\left(\mathrm{~min} / \mathrm{mm}^{2}\right)$ was found out. This relation is based on previous works about the development of the temperature field in concrete structures exposed to fire by Wickström [35]. Specifically, in Fig. 8c, this relation between $\theta_{s, e q}$ and $R / u_{s}^{2}$ is displayed for 
CHS columns, which is very similar for the rest of the section shapes. By using this relation, a non-linear regression analysis was performed:

$$
\theta_{\mathrm{s}, e q}=\chi_{3} \cdot\left(R / u_{s}^{2}\right)^{3}+\chi_{2} \cdot\left(R / u_{s}^{2}\right)^{2}+\chi_{1} \cdot\left(R / u_{s}^{2}\right)+\chi_{0}
$$

where the $\chi$ coefficients depend on the section shape and concrete cover, see Table 4 .

In this case, the influence of the section factor $\left(A_{m} / V\right)$ was not found as relevant as for the concrete core and steel tube equivalent temperature, being the fire exposure time and the concrete cover the main variables which affect the equivalent temperature of the reinforcement.

It is important to note that the temperature provided by this simplified method is an equivalent temperature from the mechanic point of view - i.e. it provides the same plastic resistance and flexural stiffness as the realistic thermal distribution -. In fact, in SHS, RHS and EHS columns it is clear that the experimental temperatures of the reinforcing bars placed near the corners are different from those located close to the edges. However, in order to be used in a simplified calculation model, a single equivalent temperature is provided. Therefore, it should be taken into account that this simplified method is only valid for specimens with the same reinforcing arrangements as those used in the parametric study (Fig. 4), which are the most commonly found in practice.

Through the non-linear regression analysis applied, a selection chart was also developed for the temperature of the reinforcing bars (Table 5), with 1.003 average error and $4.42 \%$ standard deviation, see Fig. 9c.

\subsection{Flexural stiffness reduction coefficients}

In Section 4, the application of the general method for composite columns from Clause 4.3.5.1 of EN-1994-1-2 [1] was studied, with flexural stiffness reduction coefficients equal to unity, showing in most cases unsafe predictions. Therefore, a set of flexural stiffness reduction coefficients which account for the effect of the thermal stresses should be applied. 
Differently from previous studies by the authors [16], [34] developed for circular and elliptical concrete-filled tubular columns, this research provides flexural stiffness reduction coefficients extended to square and rectangular columns through the results of the extensive parametric study presented previously. Also the buckling curve applied is assessed for all cases.

In this study, the value of the concrete flexural stiffness coefficient is fixed to $\varphi_{c, \theta}=0.8$ , when the initial tangent stiffness (calculated as $3 / 2$ times the secant modulus) is used. Therefore, if the secant modulus of concrete is used, this coefficient $\varphi_{c, \theta}$ equals 1.2. This assumption matches with previous works by the authors [16], [18], [3]. The choice of this value was proved by Renaud [30].

$$
E_{c, \theta, t}=3 / 2 \cdot E_{c, \theta, \mathrm{sec}} \rightarrow 0,8 \cdot E_{c, \theta, t}=0,8 \cdot\left(3 / 2 \cdot E_{c, \theta, \mathrm{sec}}\right)=1,2 \cdot E_{c, \theta, \mathrm{sec}}
$$

The procedure followed for deriving the values of the flexural stiffness reduction coefficients for the steel tube and reinforcement is explained hereafter. Through the parametric studies results, the buckling coefficient for each column was obtained as the numerical buckling load divided by the cross-sectional plastic resistance at elevated temperature corresponding to the failure time.

$$
\chi^{N U M}=\frac{N_{f i, R d}^{N U M}}{N_{f i, p l, R d}}
$$

By means of this buckling coefficient, the relative slenderness of the columns at elevated temperature $\lambda_{\theta}^{N U M}$ was obtained from the corresponding buckling curve. In this work, buckling curves " $a$ " and " $b$ " were used for unreinforced and reinforced columns respectively, instead of curve "c", which is prescribed in Clause 4.3.5.1 of EN 1994-1-2 [1]. This assumption produced the best fit to the parametric studies results, and is in line with the recommended buckling curves in EN 1994-1-1 [21] for concrete-filled tubular columns at room temperature.

With this value, the elastic critical load in the fire situation were obtained as follows: 


$$
N_{f i, c r}^{N U M}=\frac{N_{f i, p l, R d}}{\left(\lambda_{\theta}^{N U M}\right)^{2}}
$$

Using the definition of the Euler buckling load, the numerical values of the stiffness reduction coefficients was derived.

$$
(E I)_{f i, e f f}^{N U M}=\frac{N_{f i, c r}^{N U M} \cdot l_{\theta}^{2}}{\pi^{2}}=\sum_{j}\left(\varphi_{c, \theta} \cdot E_{c, \theta} \cdot I_{c}\right)+\left(\varphi_{a, \theta} \cdot E_{a, \theta} \cdot \mathrm{I}_{a}\right)+\left(\varphi_{s, \theta} \cdot E_{s, \theta} \cdot I_{s}\right)
$$

The next step of the procedure was to derive the steel flexural stiffness reduction coefficient $\varphi_{a, \theta}$ from the unreinforced specimens, calculated by means of eq. (27):

$$
\varphi_{a, \theta}=\frac{(E I)_{f i, e f f}^{N U M}-\sum_{j}\left(\varphi_{c, \theta} \cdot E_{c, \theta} \cdot I_{c}\right)}{E_{a, \theta} \cdot I_{a}}
$$

By maintaining this value for the steel coefficient, the reduction coefficient for the reinforcement was obtained from eq. (28):

$$
\varphi_{\mathrm{s}, \theta}=\frac{(E I)_{f i, e f f}^{N U M}-\sum_{j}\left(\varphi_{c, \theta} \cdot E_{c, \theta} \cdot I_{c}\right)-\left(\varphi_{\mathrm{a}, \theta} \cdot E_{\mathrm{a}, \theta} \cdot I_{a}\right)}{E_{\mathrm{s}, \theta} \cdot I_{s}}
$$

Following this procedure, the numerical value for the flexural stiffness reduction coefficient was obtained for each column computed in the parametric studies. Subsequently, a statistical analysis of these values was developed obtaining complex functions of the different variables that interact in the problem, such as the member slenderness $\left(l_{\theta} / D\right)$, the crosssectional slenderness $(D / t)$, the section factor $\left(A_{m} / V\right)$ and the fire exposure time $(R)$. Through a correlation analysis, these selected variables showed the strongest dependency with the flexural stiffness reduction coefficient. Therefore, the following shape of the function was proposed for the steel reduction coefficient, where each term represents the influence of an independent variable:

$$
\varphi_{a, \theta}=\varphi_{a, \theta, 1}\left(A_{m} / V\right) \cdot \varphi_{a, \theta, 2}\left(l_{\theta} / D\right) \cdot \varphi_{a, \theta, 3}(D / t) \cdot \varphi_{a, \theta, 4}(R)
$$


The shape of each term was based on similar previous works ([16], [34]) as follows:

$$
\varphi_{a, \theta, i}(x)=a_{0}+a_{1}(x)^{a_{2}}
$$

All these proposed functions, detailed for each cross-section shape, are shown in Table 6.

Regarding the flexural stiffness reduction coefficient for the reinforcement, similar functions were developed (eq.(31)). In this case, only two variables were found to interact in the problem: the section factor $\left(A_{m} / V\right)$ and the fire exposure time $(R)$.

$$
\varphi_{s, \theta}=\varphi_{s, \theta, 1}\left(A_{m} / V\right) \cdot \varphi_{s, \theta, 2}(R)
$$

Different functions were adjusted for different reinforcement levels. Specifically, different values are shown in Table 7 for percentages of reinforcement lower than $2.5 \%$ and for percentages between $2.5 \%$ and $5 \%$.

Finally, the results shown in Fig. 10 were obtained by applying these proposed reduction coefficients for concrete, steel and reinforcement to all concentrically loaded cases from the parametric studies (3000 specimens approximately). As can be seen, safe predictions are obtained on average, with a reduced dispersion of results.

The criteria used in this work for verifying the accuracy of the developed simplified design method was that approved by CEN/TC250/SC4 Horizontal Group Fire [36], which prescribes that three criteria should be met for a calculation method to be considered accurate. Firstly, the calculation result shall not be on the unsafe side by more than $15 \%$ of the reference result, secondly a maximum of $20 \%$ of individual calculation results shall be on the unsafe side and thirdly the mean value of all percentage differences between calculation results and reference results shall be on the safe side.

Taking all the calculation points from the parametric studies results, the average error lies on the safe side with a value of 1.2 and a standard deviation of 0.16 . A maximum deviation on the unsafe side of $14.9 \%(<15 \%)$ is observed and only $8 \%(<20 \%)$ of the cases lie on the unsafe 
side. Therefore, all the prescribed criteria are met (see Table 8). On the contrary, the maximum deviation on the safe side is $47.1 \%$, although it should be noted that the criteria from CEN/TC250/SC4 do not limit the error on the safe side.

Therefore, a significant improvement as compared to the current methods can be observed by comparing Fig. 6a-b against Fig. 10.

It must be pointed out that for the case of unreinforced CHS and SHS columns with a relative slenderness $\bar{\lambda}$ over 0.5 the method cannot be used, as a consequence in these columns a minimum percentage of reinforcement of $2.5 \%$ is required for the application of the method. This clause should be carefully taken into account when applying the method, as described in Section 5.4.

Besides, it must be highlighted that the stiffness reduction coefficients are developed using advanced temperature field from numerical simulations. As a consequence, the equivalent temperature concept, developed in section 5.1, is not necessarily linked with the mechanical proposal. These stiffness reduction coefficients can also be used in combination with realistic temperature field obtained through advanced calculation tools.

In order to complete the proposal of the simplified design method, a new approach for eccentrically loaded CFST columns is developed next.

\subsection{Reduction coefficients for eccentricity}

As was shown in Fig. 7, EN 1994-1-2 [1] does not provide an accurate method to predict the fire resistance of eccentrically loaded CFST columns. For this reason, a new proposal to account for eccentricity was developed, through the parametric studies results. Using the same approach from Annex G of EN 1994-1-2 [1] for partially encased steel sections, eq.(32) was proposed:

$$
N_{f i, R d, \delta}=\alpha \cdot\left(\frac{N_{R d, \delta}}{N_{R d}}\right)_{\text {room }} \cdot N_{f i, R d}
$$


This formulation assumes that the relation between concentric and eccentric ultimate load

in the fire situation $\left(N_{f i, R d, \delta} / N_{f i, R d}\right)$ and at room temperature $\left(N_{R d, \delta} / N_{R d}\right)$ are similar. Note that the concentric and eccentric ultimate loads of the column at room temperature should be computed following the design rules in EN 1994-1-1 [16].

This relation was adjusted through the coefficient $\alpha$, for which a formulation was developed as a combination of the contribution of the different parameters.

\section{Circular and square cross-sections}

$$
\alpha=\alpha_{A_{m} / V} \cdot \alpha_{D / t} \cdot \alpha_{R} \cdot \alpha_{s}
$$

where:

$$
\begin{array}{l|l}
\alpha_{A_{m} / V}=0.0089 \cdot\left(A_{m} / V\right)+0.443 & \\
\alpha_{D / \mathrm{t}}=-0.0049 \cdot(D / t)+0.5426 & \left(l_{\theta} / \mathrm{D} \leq 15\right) \\
\alpha_{R}=6.9598 \cdot R^{-0.221} & \\
\alpha_{A_{m} / V}=1 & \left(l_{\theta} / \mathrm{D}>15\right) \\
\alpha_{D / \mathrm{t}}=1 & \\
\alpha_{R}=0.92 &
\end{array}
$$

and

$$
\begin{array}{ll}
\alpha_{s}=0.8 & (\rho=0 \%) \\
\alpha_{s}=-6.44 \cdot 10^{-4}\left(l_{\theta} / D\right)^{2}+4.17 \cdot 10^{-2}\left(l_{\theta} / D\right)+0.553 & (0 \%<\rho \leq 2.5 \%) \\
\alpha_{s}=-7 \cdot 10^{-4}\left(l_{\theta} / D\right)^{2}+4.54 \cdot 10^{-2}\left(l_{\theta} / D\right)+0.601 & (2.5 \%<\rho \leq 5 \%)
\end{array}
$$

but

$$
\text { when } R \geq 60 \min \& \rho>0 \% \text { then } \alpha=0.92 \cdot \alpha_{s}
$$

This formulation was built based on the same dependent variables as for the flexural stiffness reductions coefficients: section factor $\left(A_{m} / V\right)$, member slenderness $\left(l_{\theta} / D\right)$, section 
slenderness $(D / t)$ and fire resistance time $(R)$. It is also assumed that the simplified design method presented in Section 5.2 of this paper for calculating the concentric axial buckling load for CFST columns in the fire situation is used.

Additionally, it should be noticed that for reinforced CHS and SHS columns and fire exposure times over 60 minutes $(R \geq 60)$, this coefficient to account for eccentricity should be simplified to $\alpha=0.92 \cdot \alpha_{s}$, instead of using the partial coefficients.

\section{Rectangular and elliptical cross-sections}

Regarding RHS and EHS columns, this coefficient $\alpha$ turns in a simpler formulation for minor axis eccentricity, acquiring a value of 0.92 for RHS columns and 0.828 for EHS.

Finally, it should be noticed that for major axis eccentricity, the formulation was developed without taking into account any possible interaction between major and minor axis. Therefore, this method cannot be applied for biaxial bending and requires that minor axis bending is prevented when eccentricity is applied about the major axis. In this case, the axial and eccentric ultimate load at room temperature and in the fire situation should be calculated for major axis. The coefficient $\alpha$ must be obtained from the next summary for RHS and EHS cross-sections:

RHS

- Minor axis

$$
\alpha=0.92
$$

- Major axis

$$
\alpha=\frac{1.296 \cdot\left(l_{\theta} / H\right)}{\left(l_{\theta} / H\right)+3 \cdot(H / B)}+2.088 \cdot 10^{-4} \cdot\left(l_{\theta} / H\right) \cdot(H / B)^{5}-130.392 \cdot 10^{-4}
$$

EHS 
- $\quad$ Minor axis

$$
\alpha=0.828
$$

- $\quad$ Major axis

$$
\alpha=\left(-1.05 \cdot 10^{-3} \cdot\left(l_{\theta} / \mathrm{H}\right)^{3}+3.86 \cdot 10^{-2} \cdot\left(l_{\theta} / \mathrm{H}\right)^{2}-0.353 \cdot\left(l_{\theta} / \mathrm{H}\right)+1.81\right) \cdot\left(-1.65 \cdot 10^{-2}(H / t)+1.3\right)
$$

Regarding this last coefficient, a new variable was included: the aspect $\operatorname{ratio}(H / B)$, which accounts for the different relations between the width and height of the section.

Once the equations of the design proposal were derived, the prediction errors were computed and an outlier detection technique was applied, in order to remove the anomalous data. In statistics, an outlier is an observation point that is distant from other observations. In this case, previous to the final assessment of the accuracy of the proposed method, the predictions for eccentrically loaded CFST columns were evaluated, showing some possible outliers.

The outlier detection technique assumes a normal distribution of the variable studied. However, the computed error did not present a normal distribution in this problem. Therefore, a transformation was carried out taking logarithms of the error values in order to normalise the distribution of the data (see Fig. 11).

Through the resulting normalised distribution, those values laying out of the $\pm 3 \sigma$ range were considered outliers and thus removed from the database. Once the ouliers were removed, the proposed method was assessed against the CEN/TC250/SC4 Horizontal Group Fire [36]criteria, presented in Section 5.2.

The results of the proposal for eccentrically loaded columns, applied to all the analysis cases from the parametric studies (17500 eccentrically loaded specimens, approximately) are presented in Fig. 12, showing accurate predictions, with the average error lying on the safe side, in contrast with the results obtained using the simplified methods provided by EN 1994-1-2 [1], previously exposed in Section 4 (Fig. 7). The accuracy parameters for the prediction of this 
proposed method against the parametric studies results are shown in Table 8, meeting the Horizontal Group Fire criteria [36]. It can be verified that, for both minor and major axis eccentricity, the average error lies on the safe side with a value over 1, the maximum deviation on the unsafe side is lower than $15 \%$ and less than $20 \%$ of the cases lie on the unsafe side.

\subsection{Applicability limits of the proposed method}

The proposed simplified design method should only be applied for CFST columns in the following conditions:

- Section factor, cross-sectional slenderness and member slenderness:

For CHS columns:

$$
\begin{aligned}
& 5 \leq A_{m} / V \leq 30 \\
& 10 \leq D / t \leq 60 \\
& 5 \leq l_{\theta} / D \leq 50
\end{aligned}
$$

For SHS columns:

$$
\begin{aligned}
& 5 \leq A_{m} / V \leq 35 \\
& 5 \leq B / t \leq 40 \\
& 5 \leq l_{\theta} / B \leq 55
\end{aligned}
$$

For EHS columns:

$$
\begin{gathered}
10 \leq A_{m} / V \leq 30 \\
5 \leq B / t \leq 20 \\
5 \leq l_{\theta} / B \leq 55 \\
H / B=2
\end{gathered}
$$

For RHS columns: 


$$
\begin{gathered}
5 \leq B / t \leq 20 \\
5 \leq l_{\theta} / B \leq 60 \\
1.5 \leq H / B \leq 3
\end{gathered}
$$

- The percentage of reinforcement should not exceed $5 \%$.

- $\quad$ The concrete strength class should be limited between C20/25 - C50/60.

- The reinforcement arrangement should be taken from Fig. 4, for the different crosssection shapes.

- For concentrically loaded unreinforced CHS and SHS columns with relative slenderness $\bar{\lambda}$ over 0.5 , a minimum amount of $2.5 \%$ of reinforcement is required.

- The relative load eccentricity $e / D, e / \mathrm{B}$ or $e / \mathrm{H}$ should not exceed 1.0.

- The method can be used for specimens with a standard fire exposure time ranging between 30 and 240 minutes.

- Interaction between major and minor axis is not considered in the proposed method for eccentrically loaded columns. Therefore, it is supposed that when eccentricity is applied about the major axis, minor axis bending is prevented.

- It is considered that differential axial displacements may occur between the outer steel tube and the concrete core, i.e., slip is considered at the top end of the columns.

\section{COMPARISON OF THE PROPOSED SIMPLIFIED DESIGN METHOD WITH EXPERIMENTAL RESULTS}

In this section, the proposed method is compared against the results of real fire tests carried out by the authors in the experimental campaign of the European Project FRISCC [31], [32]. These experimental campaign included all cross-section shapes studied, axially and eccentrically loaded specimens and reinforced or unreinforced columns. The comparison is developed in terms of failure load at the fire exposure time reached in the experimental tests. It is worth noting that specimens R5, R11 and E11 were omitted from this comparison due to the 
fact that the proposed simplified method does not take into account biaxial bending, which was observed for the referred specimens. These omitted specimens were loaded under low relative eccentricity (0.2) on their major axis, minor axis bending not being prevented, therefore interaction between minor and major axis was observed.

Fig. 13 and Table 9 show this comparison, including additionally the results of the application of the general method in Clause 4.3.5.1 of EN 1994-1-2 [1], assuming flexural stiffness reduction coefficients equal to unity (EC4(1)). As previously revealed in Section 4, and confirmed here, the EC4(1) method leads to unsafe predictions with an average error lower than unity, which is found for all cross-section shapes. On the contrary, the predictions of the proposed simplified design method lay on the safe side for all cases. It is worth mentioning that the conservativeness of the proposed method is due to the severe accuracy criteria used, taken from the Horizontal Group Fire [36], which forces most of the predictions to be on the safe side.

\section{DESIGN EXAMPLE}

In this section, a design example is presented in order to illustrate the application of the proposed method for evaluating the fire resistance of CFST columns. This worked example corresponds to a reinforced CHS column exposed to a standard fire period of 60 minutes (R60). The member considered belongs to the top storey of a continuous column. The geometrical and material properties of the column are as follows:

- Column length: $4000 \mathrm{~mm}$

- Cross-sectional dimensions (CHS): $D \times t=273 \times 10 \mathrm{~mm}$

- Reinforcement: $6 \phi 16 \mathrm{~mm}$

- Concrete cover (rebar axis distance): $\mathrm{u}_{\mathrm{s}}=35 \mathrm{~mm}$

- $\quad$ Steel yield strength: $f_{y}=355 \mathrm{MPa}$

- Reinforcing bars yield strength: $f_{s}=500 \mathrm{MPa}$ 
- Compressive concrete strength: $f_{c}=30 \mathrm{MPa}$

As a first step, the section factor, cross-sectional slenderness and member slenderness needed for the application of the method are computed:

- Section factor: $A_{m} / V=4 / D=4 / 273 \times 1000=14.65 \mathrm{~m}^{-1}$

- Member slenderness in the fire situation: $l_{\theta} / D=(\beta \cdot l) / D=(0.7 x 4000) / 273=10.26$

- Cross-sectional slenderness: $D / t=273 / 10=27.3$

Note that according to Clauses (9) and (10) of 4.3.5.1 in EN 1994-1-2 [1], for a column fully connected to the column above and below and also located on the top floor, the buckling length in the fire situation is considered as 0.7 times the column length.

\section{Calculation of the equivalent temperatures}

On a first stage, the equivalent temperatures for each component of the composite section must be obtained by means of the proposed equations from Section 5.1 or alternatively Table 3 and Table 5 .

For the concrete core:

$$
\begin{aligned}
& \theta_{c, e q}=81.801-5.046 R+0.003 R^{2}-15.07 A_{m} / V+0.331\left(A_{m} / V\right)^{2}-0.875 R \cdot A_{m} / V \\
& +7.428 R^{0.842} \cdot\left(A_{m} / V\right)^{0.714}= \\
& =81.801-5.046 \cdot 60+0.003 \cdot 60^{2}-15.07 \cdot 14.65+0.331(14.65)^{2}-0.875 \cdot 60 \cdot 14.65 \\
& +7.428 \cdot 60^{0.842} \cdot(14.65)^{0.714}=456^{\circ} C
\end{aligned}
$$

For the steel tube:

$$
\begin{aligned}
& \theta_{\mathrm{a}, e q}=-824.667-5.579 R+0.007 R^{2}-0.009 R \cdot A_{m} / V+645.076 R^{0.269} \cdot\left(A_{m} / V\right)^{0.017}= \\
& =-824.667-5.579 \cdot 60+0.007 \cdot 60^{2}-0.009 \cdot 60 \cdot 14.65+645.076 \cdot 60^{0.269} \cdot(14.65)^{0.017}=889^{\circ} C
\end{aligned}
$$

For the reinforcement $\left(\mathrm{u}_{\mathrm{s}}=35 \mathrm{~mm}\right)$ :

$$
\begin{aligned}
& \theta_{\mathrm{s}, e q}=0 \cdot\left(t / u_{s}^{2}\right)^{3}-12732 \cdot\left(t / u_{s}^{2}\right)^{2}+6518 \cdot\left(t / u_{s}^{2}\right)+91.208= \\
& =0 \cdot\left(60 / 35^{2}\right)^{3}-12732 \cdot\left(60 / 35^{2}\right)^{2}+6518 \cdot\left(60 / 35^{2}\right)+91.208=380^{\circ} \mathrm{C}
\end{aligned}
$$


Albero V, Espinos A, Romero ML, Hospitaler A, Bihina G, Renaud C. Proposal of a new method in EN1994-1-2 for the fire design of concrete-filled steel tubular columns. Eng. Struct. 2016; 128:237-55. doi: 10.1016/j.engstruct.2016.09.037 


\section{Evaluation of the design buckling load in the fire situation in case of concentric load}

Once the equivalent temperatures are obtained, the cross-sectional plastic resistance can be easily calculated:

$$
\begin{aligned}
& N_{f i, p l, R d}=A_{a} f_{y}\left(\theta_{a, e q}\right)+A_{c} f_{c}\left(\theta_{\mathrm{c}, e q}\right)+A_{s} f_{s}\left(\theta_{\mathrm{s}, e q}\right)= \\
& =8262.4 \mathrm{~mm}^{2} \cdot k_{y}\left(889^{\circ} \mathrm{C}\right) \cdot 355 \mathrm{MPa}+49066.2 \mathrm{~mm}^{2} \cdot k_{c}\left(456^{\circ} \mathrm{C}\right) \cdot 30 \mathrm{MPa}+ \\
& +1206.4 \mathrm{~mm}^{2} \cdot k_{y}\left(380^{\circ} \mathrm{C}\right) \cdot 500 \mathrm{MPa}= \\
& =8262.4 \cdot 0.065 \cdot 355+49066.2 \cdot 0.666 \cdot 30+1206.4 \cdot 0.952 \cdot 500 \mathrm{MPa}=1746.7 \mathrm{kN}
\end{aligned}
$$

The partial factors of the materials in the fire situation $\gamma_{M, f i, i}$ have been taken as unity, as per Clause 2.3 of EN 1994-1-2 [1].

On a second stage, the flexural stiffness reduction coefficients $\varphi_{a, \theta}, \varphi_{\mathrm{c}, \theta}$ and $\varphi_{\mathrm{s}, \theta}$ should be calculated through the equations and tables provided in Section 5.2, for subsequently obtaining the effective flexural stiffness of the column.

The reduction coefficient of the concrete core is equal to 0.8 , while the reduction coefficients for the steel tube and reinforcement are obtained as given next.

For the steel tube, with a member slenderness in the fire situation $l_{\theta} / D=10.26<12$ (see Table 6):

$$
\begin{aligned}
& \varphi_{a, \theta}=\varphi_{a, \theta, 1}\left(A_{m} / V\right) \cdot \varphi_{a, \theta, 2}\left(l_{\theta} / D\right) \cdot \varphi_{a, \theta, 3}(D / t) \cdot \varphi_{a, \theta, 4}(R)=\left[6.05-1.16\left(A_{m} / V\right)^{0.417}\right] \\
& \cdot\left[0.55+0.082\left(l_{\theta} / \mathrm{D}\right)^{0.979}\right] \cdot\left[566.37-565.25(D / t)^{2.21 \cdot 10^{-4}}\right] \cdot\left[0.116+8.84 \cdot 10^{-12}(R)^{4.285}\right]= \\
& =2.496 \cdot 1.35 \cdot 0.706 \cdot 0.116=0.276
\end{aligned}
$$

For the reinforcement, with a percentage of reinforcement under $2.5 \%$ (see Table 7):

$$
\varphi_{s, \theta}=\varphi_{s, \theta, 1}\left(A_{m} / V\right) \cdot \varphi_{s, \theta, 2}(R)=\left[0.23+0.018 \cdot\left(A_{m} / V\right)\right] \cdot[0.8-0.001 \cdot(R)]=0.494 \cdot 0.74=0.37
$$

Therefore, the effective flexural stiffness of the column in the fire situation results: 


$$
\begin{aligned}
& (E I)_{f i, e f f}=\varphi_{a, \theta} E_{a}\left(\theta_{a, e q}\right) I_{a}+\varphi_{\mathrm{c}, \theta} E_{c}\left(\theta_{\mathrm{c}, e q}\right) I_{c}+\varphi_{\mathrm{s}, \theta} E_{s}\left(\theta_{\mathrm{s}, e q}\right) I_{s}= \\
& =0.276 \cdot 210000 \mathrm{MPa} \cdot k_{E}\left(889^{\circ} \mathrm{C}\right) \cdot 71540925.18 \mathrm{~mm}^{4}+ \\
& +0.8 \cdot 3 / 2 \cdot k_{c}\left(456^{\circ} \mathrm{C}\right) \cdot 30 \mathrm{MPa} / \varepsilon_{c u}\left(456^{\circ} \mathrm{C}\right) \cdot 196049158.3 \mathrm{~mm}^{4}+ \\
& +0.37 \cdot 210000 \mathrm{MPa} \cdot k_{E}\left(380^{\circ} \mathrm{C}\right) \cdot 5069324.2 \mathrm{~mm}^{4}= \\
& 0.27 \cdot 210000 \cdot 0.07 \cdot 71540925.18+1.2 \cdot 0.666 \cdot 30 / 0.012798 \cdot 196049158.3+ \\
& +0.37 \cdot 210000 \cdot 0.592 \cdot 2069324.2=879.512 \mathrm{kN} \cdot \mathrm{m}^{2}
\end{aligned}
$$

Now, the Euler buckling load and the relative slenderness at elevated temperature can be calculated as follows:

$$
\begin{gathered}
N_{f i, c r}=\pi^{2}(E I)_{f i, e f f} / l_{\theta}^{2}=\pi^{2} 879.512 \cdot 10^{9} \mathrm{~N} \cdot \mathrm{mm}^{2} /(0.7 \cdot 4000)^{2}=1107.2 \mathrm{kN} \\
\bar{\lambda}_{\theta}=\sqrt{N_{f i, p l, R} / N_{f i, c r}}=\sqrt{1746.7 / 1107.2}=1.26
\end{gathered}
$$

Using buckling curve "b", corresponding to reinforced columns, a buckling coefficient $\chi=0.45$ is obtained. Therefore, the design value of the buckling load of the column in axial compression, after 60 minutes of fire exposure, is:

$$
N_{f i, R d}=\chi N_{f i, p l, R d}=0.45 \cdot 1746.7=786.02 \mathrm{kN}
$$

\section{Evaluation of the design buckling load in the fire situation in case of eccentric load}

Additionally, the fire resistance of the same column loaded under a relative eccentricity of $e / D=0.5$ is evaluated. Following the design rules in EN 1994-1-1 [16], the concentric and eccentric ultimate load of the column at room temperature are computed:

$$
N_{R d}=4373.6 \mathrm{kN} \quad N_{R d, \delta}=1467.8 \mathrm{kN}
$$

The procedure to obtain these values at room temperature is not described here, as it is out of the scope of this work. The reader is addressed to EN 1994-1-1 [16] for more details on the application of the method.

Using the proposed equation for eccentrically loaded columns in the fire situation from Section 5.3, the ultimate load can be finally evaluated:

$$
N_{f, R d, \delta}=\alpha \cdot\left(\frac{N_{R d, \delta}}{N_{R d}}\right)_{\text {room }} \cdot N_{f i, R d}
$$


where $\alpha=0.92 \alpha_{s}$ for $R \geq 60$ and reinforced CHS columns.

$$
\begin{gathered}
\alpha_{s}=-6.44 \cdot 10^{-4}\left(l_{\theta} / D\right)^{2}+4.17 \cdot 10^{-2}\left(l_{\theta} / D\right)+0.553 \quad(0 \%<\rho \leq 2.5 \%) \\
\alpha=0.92 \cdot\left(-6.44 \cdot 10^{-4}(10.26)^{2}+4.17 \cdot 10^{-2}(10.26)+0.553\right)=0.84 \\
N_{f i, R d, \delta}=0.84 \cdot\left(\frac{1467.8}{4373.6}\right) \cdot 786.02=221.6 \mathrm{kN}
\end{gathered}
$$

\section{SUMMARY AND CONCLUSIONS}

This paper presents a simplified design method for evaluating the fire resistance of unprotected CFST columns under ISO standard fire conditions, based on the general method in EN 1994-1-2 [1] for composite columns, extended over the current applicability limits. This proposal includes innovative shapes such as elliptical hollow sections and provides safe predictions for columns with relative slenderness at ambient temperature up to 2.0. Therefore, this method solves the current limitations of Annex H in EC4, which is currently limited to relative slenderness at ambient temperature under 0.5 . It is recommended in the method that buckling curves "a" and "b" should be applied for unreinforced and reinforced axially loaded columns, respectively, instead of curve "c", leading to a proposal which is in line with the buckling curves used in EN 1994-1-1 for cold design. Besides, coefficients to take into account large relative eccentricities up to $e / D=1$ are provided.

The method was developed through an extensive parametric study which included 20.500 numerical analysis cases approximately. This study was carried out through the numerical models developed by UPV and CTICM, which were validated against the results of a previous experimental campaign carried out by the authors within the European Project FRISCC.

Finally, it is important to note that the proposed simplified design method considers that differential axial displacements between the outer steel tube and the concrete core are allowed 
- i.e. free slip at top end of the column - and recommends a minimum percentage of reinforcement of a $2.5 \%$ for CHS and SHS columns with relative slenderness over 0.5.

\section{ACKNOWLEDGEMENTS}

The authors would like to express their sincere gratitude to the European Union for the help provided through the Project RFSR-CT-2012-00025, carried out with a financial grant of the Research Programme of the Research Fund for Coal and Steel. 


\section{REFERENCES}

[1] CEN. EN 1994-1-2, Eurocode 4: Design of composite steel and concrete structures. Part 1-2: General rules - Structural fire design. Brussels, Belgium: Comité Européen de Normalisation; 2005.

[2] Romero ML, Moliner V, Espinos A, Ibañez C, Hospitaler A. Fire behavior of axially loaded slender high strength concrete-filled tubular columns. J Constr Steel Res. 2011;67:195365 .

[3] Renaud C, Joyeux D, Kruppa J. Improvement and extension of the simple calculation method for fire resistance of unprotected concrete filled hollow columns. In: 15Q-12/03 Crp, editor. Saint-Rémy-lès-Chevreuse, France: Centre Technique Industriel de la Contruction Métallique (CTICM); 2004.

[4] Leskela MV. Background document to New Annex H/EN 1994-1-2. Draft 4.10.2010 prepared for the meeting in Valencia. Finland: University of Oulu; 2010.

[5] Zhao XL, Han LH, Lu H. Concrete-filled tubular members and connections. Spon Press. 2010.

[6] Han LH, Zhao XL, Yang YF, Feng JB. Experimental study and calculation of fire resistance of concrete-filled hollow steel columns. Journal of Structural Engineering. 2003;129:346-56.

[7] Han LH, Yang YF, Xu L. An experimental study and calculation on the fire resistance of concrete-filled SHS columns. J Constr Steel Res. 2003;59(4):427-52.

[8] Kodur VKR. Performance-based fire resistance design of concrete-filled steel columns. J Constr Steel Res. 1999;51:21-36.

[9] Kodur VKR. Guidelines for fire resistant design of concrete-filled steel HSS columns State-of-the-art and research needs. Steel Structures. 2007;7:173-82.

[10] Kodur VKR, Mackinnon DH. Design of concrete-filled hollow structural steel columns for fire endurance. Engineering Journal. 2000;37:13-24.

[11] Park S, Chung K, Choi S. A study on failure prediction and design equation of concrete filled square steel tube columns under fire condition. Steel Structures. 2007;7(3):183-91.

[12] Park S, Choi S, Chung K. A study on the fire-resistance of concrete-filled steel square tube columns without fire protection under constant central axial loads. . Steel Compos Struct. 2008;8(6):491-510.

[13] DBJ. DBJ13-51-2003: Technical specification for concrete-filled steel tubular structures (in Chinese). Fuzhou: The Construction Department of Fujian Province; 2003. 
[14] ANUHT. Fire resistance design of non-insulated CFT columns - guidelines, technical explanations and deign examples. 2004.

[15] Lennon T, Moore DB, Wang TC, Bailey CG. Designers' guide to EN 1991-1-2, EN 1992-1-2, EN 1993-1-2 and EN 1994-1-2. Thomas Telford Limited. 2007.

[16] Espinos A, Romero ML, Hospitaler A. Simple calculation model for evaluating the fire resistance of unreinforced concrete filled tubular columns. Engineering Structures. 2012;42:231-44.

[17] Ibañez C, Aguado JV, Romero ML, Espinos A, Hospitaler A. Fire design method for concrete filled tubular columns based on equivalent concrete core cross-section. Fire Safety Journal. 2015;78:10-23.

[18] Aribert JM, Renaud C, Zhao B. Simplified fire design for composite hollow-section columns. Proc Inst Civil Eng-Struct Build. 2008;161:325-36.

[19] Leskela MV. Inconsistencies in the fire design rules of composite columns to EN 19941-2. Steel concrete composite and hybrid structures. Leeds, England;2009. p. 489-94.

[20] CEN. EN 1993-1-1, Eurocode 3: Design steel structures. Part 1-1: General rules and rules for buildings. Brussels, Belgium: Comité Européen de Normalisation; 2005.

[21] CEN. EN 1994-1-1, Eurocode 4: Design of composite steel and concrete structures. Part 1-1: General rules and rules for buildings. Brussels, Belgium: Comité Européen de Normalisation; 2004.

[22] ABAQUS. ABAQUS/standard version 6.13 user's manual.

[23] Espinos A, Romero ML, Hospitaler A. Advanced model for predicting the fire response of concrete filled tubular columns. J Constr Steel Res. 2010;66:1030-46.

[24] CEN. EN 1991-1-2, Eurocode 1: Actions on structures. Part 1-2. General actions actions on structures exposed to fire. Brussels, Belgium: Comité Européen de Normalisation; 2002.

[25] Garzón-Roca J, Adam JM, Calderón PA, Valente IB. Finite element modelling of steelcaged RC columns subjected to axial force and bending moment. Engineering Structures. 2012;40:168-86.

[26] CEN. EN 1993-1-2, Eurocode 3: Design steel structures. Part 1-2: General rules Structural fire design. Brussels, Belgium: Comité Européen de Normalisation; 2005.

[27] CEN. EN 1992-1-2, Eurocode 2: Design of concrete structures. Part 1-2: General rules - Structural fire design. Brussels, Belgium: Comité Européen de Normalisation; 2004. 
[28] Zhao B, Aribert JM. Finite element method for steel-concrete composite frames taking account of slip and large displacements. European Journal of Finite Element. 1996;5:221-49.

[29] Renaud C, Aribert JM, Zhao B. Advanced numerical model for the fire behaviour of composite columns with hollow steel section. Steel Compos Struct. 2003;3:75-95.

[30] Renaud C. Modélisation numérique, expérimentation et dimensionnement pratique des poteaux mixtes avec profil creux exposés à l'incendie [In French]. INSA de Rennes, France 2003.

[31] Espinos A, Romero ML, Serra E, Hospitaler A. Circular and square slender concretefilled tubular columns under large eccentricities and fire. J Constr Steel Res. 2015;110:90-100.

[32] Espinos A, Romero ML, Serra E, Hospitaler A. Experimental investigation on the fire behaviour of rectangular and elliptical slender concrete-filled tubular columns. Thin-Walled Structures. 2015;93:137-48.

[33] CEN. EN 1992-1-1, Eurocode 2: Design of concrete structures. Part 1-1: General rules and rules for buildings. Brussels, Belgium: Comité Européen de Normalisation; 2004.

[34] Espinos A, Romero ML, Hospitaler A. Fire design method for bar-reinforced circular and elliptical concrete filled tubular columns. Engineering Structures. 2013;56:384-95.

[35] Wickström U. A very simple method for estimating temperature in fire exposed concrete structures. Sweden: Swedish national testing institute; 1986.

[36] Fire C-T-HG. EUROCODES - FIRE PARTS. Proposal for a Methodology to check the Accuracy of Assessment Methods. France: CTICM; 2014. 
Albero V, Espinos A, Romero ML, Hospitaler A, Bihina G, Renaud C. Proposal of a new method in EN1994-1-2 for the fire design of concrete-filled steel tubular columns. Eng. Struct. 2016; 128:237-55. doi: 10.1016/j.engstruct.2016.09.037

\section{FIGURES}

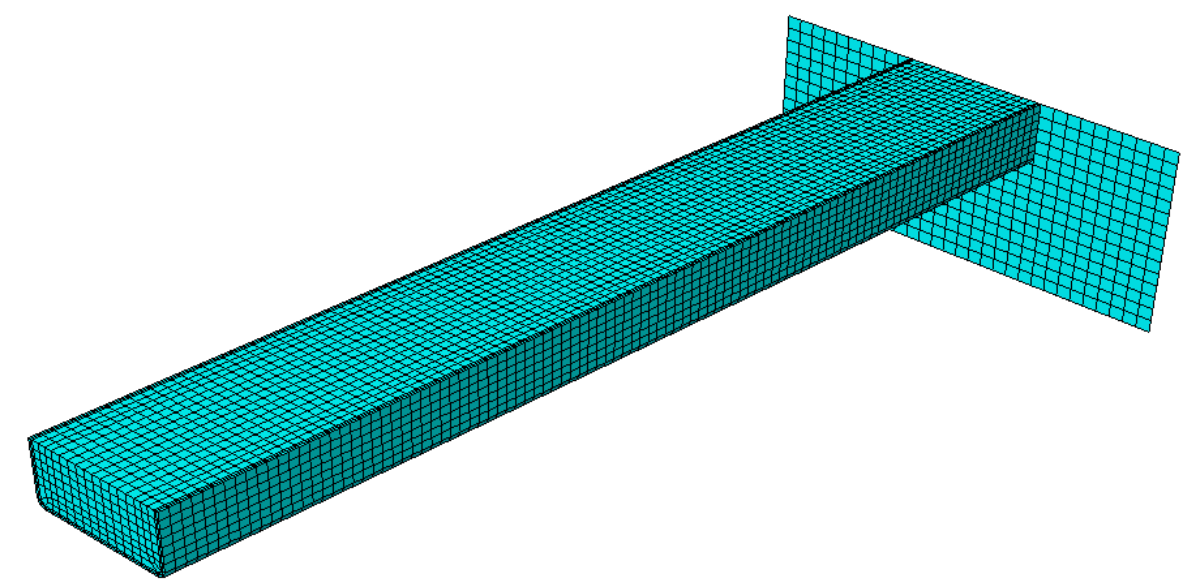

Fig. 1 Finite element mesh for one column specimen, generated with the three-dimensional model from UPV. 
Albero V, Espinos A, Romero ML, Hospitaler A, Bihina G, Renaud C. Proposal of a new method in EN1994-1-2 for the fire design of concrete-filled steel tubular columns. Eng. Struct. 2016; 128:237-55. doi: 10.1016/j.engstruct.2016.09.037

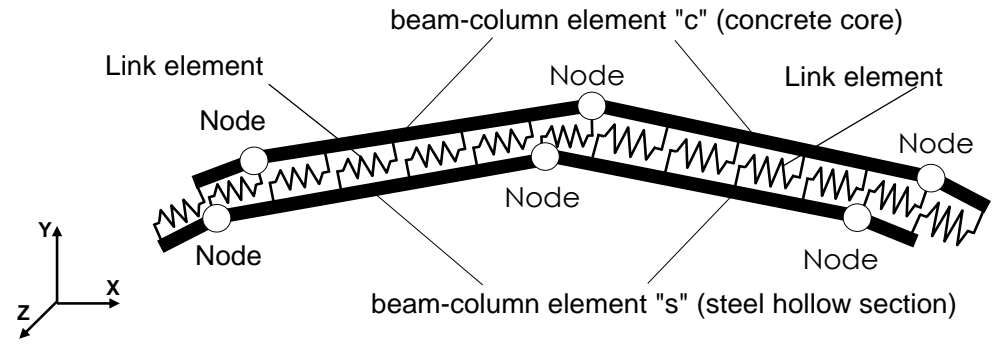

Fig. 2 Specific finite beam element from CTICM two-dimensional model. 

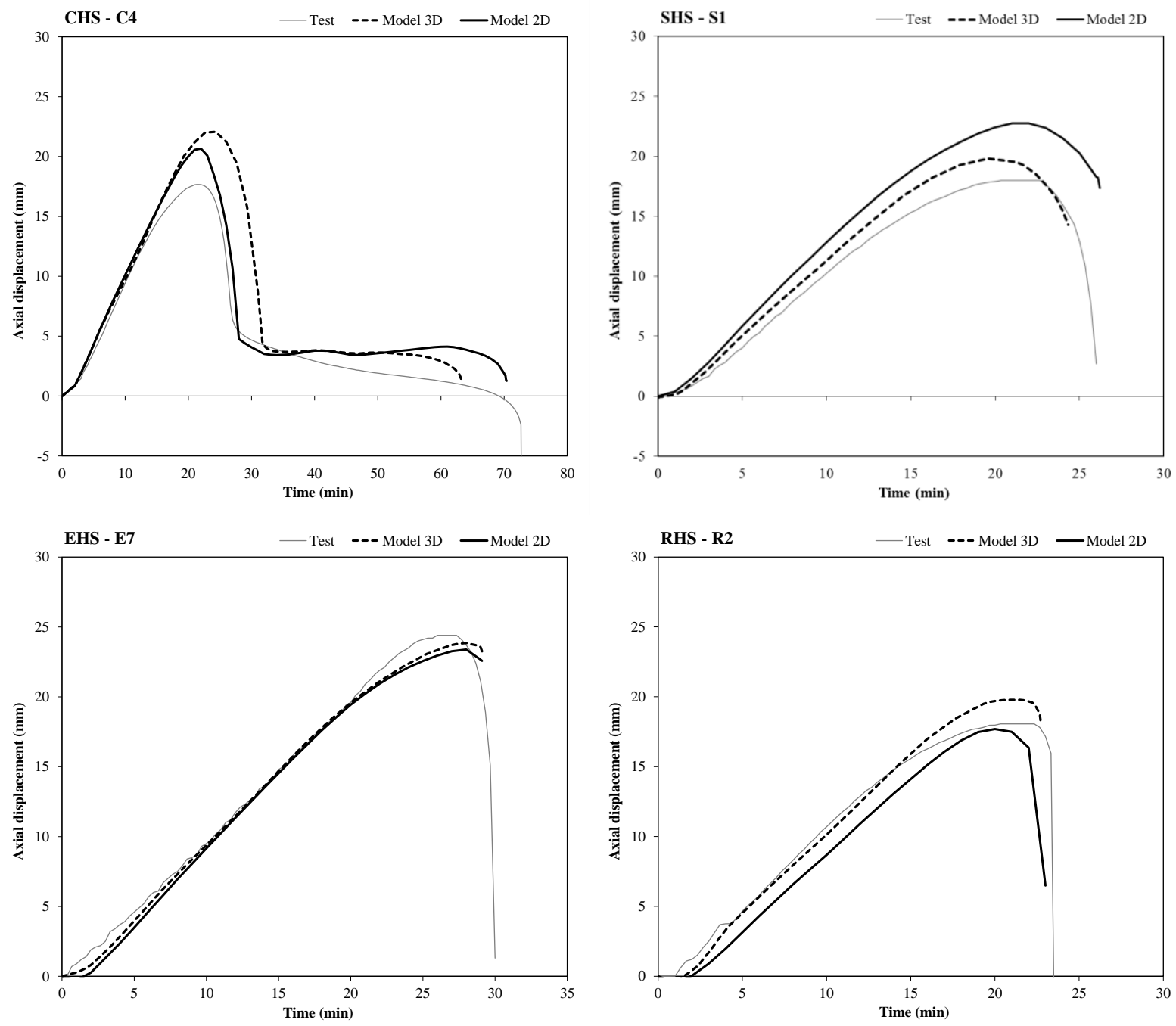

Fig. 3Experimental behaviour compared to those of 2D and 3D models. 
Albero V, Espinos A, Romero ML, Hospitaler A, Bihina G, Renaud C. Proposal of a new method in EN1994-1-2 for the fire design of concrete-filled steel tubular columns. Eng. Struct. 2016; 128:237-55. doi: 10.1016/j.engstruct.2016.09.037

a) $\mathrm{CHS}$
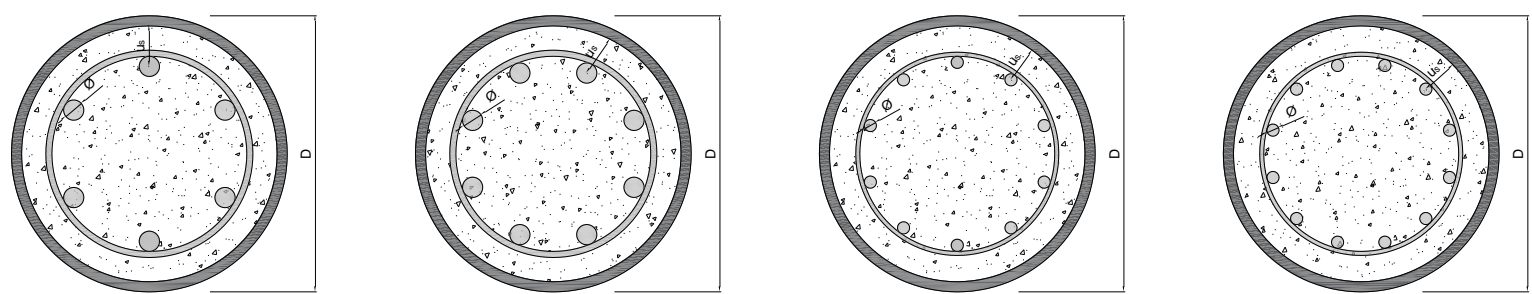

b) SHS
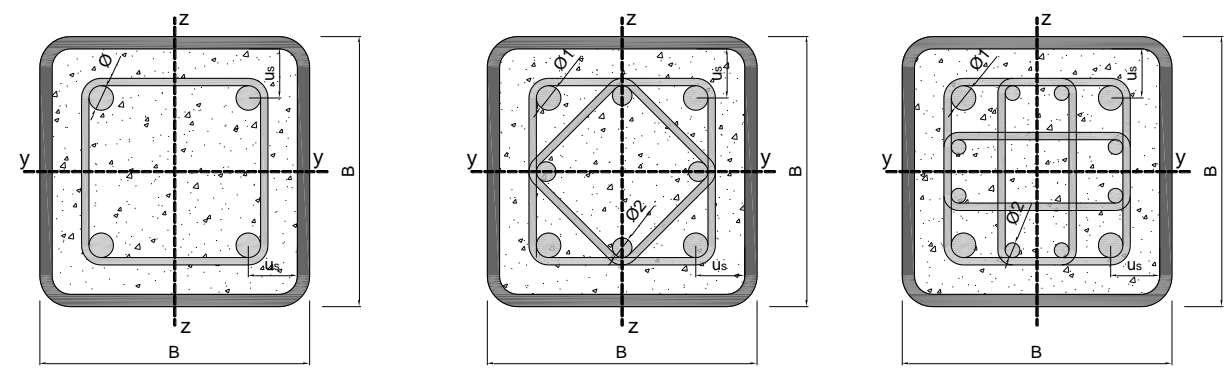

c) RHS
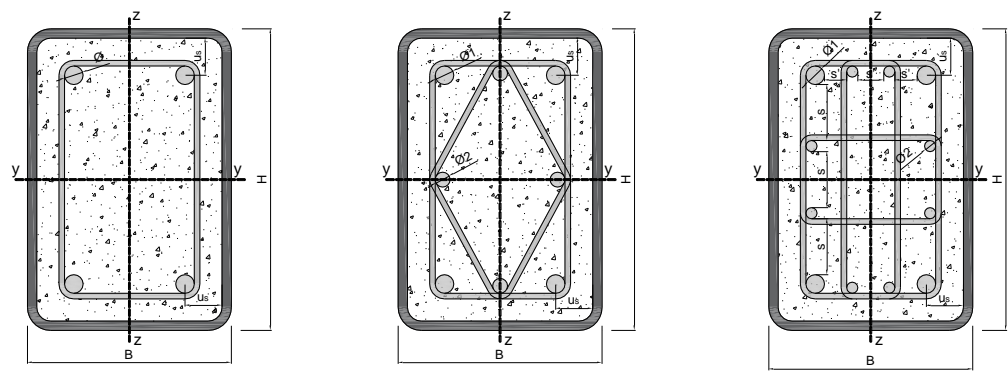

d) EHS

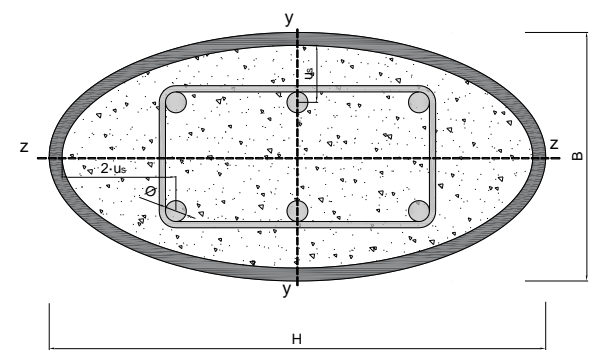

Fig. 4 Reinforcement arrangements used in the parametric studies. 
Albero V, Espinos A, Romero ML, Hospitaler A, Bihina G, Renaud C. Proposal of a new method in EN1994-1-2 for the fire design of concrete-filled steel tubular columns. Eng. Struct. 2016; 128:237-55. doi: 10.1016/j.engstruct.2016.09.037

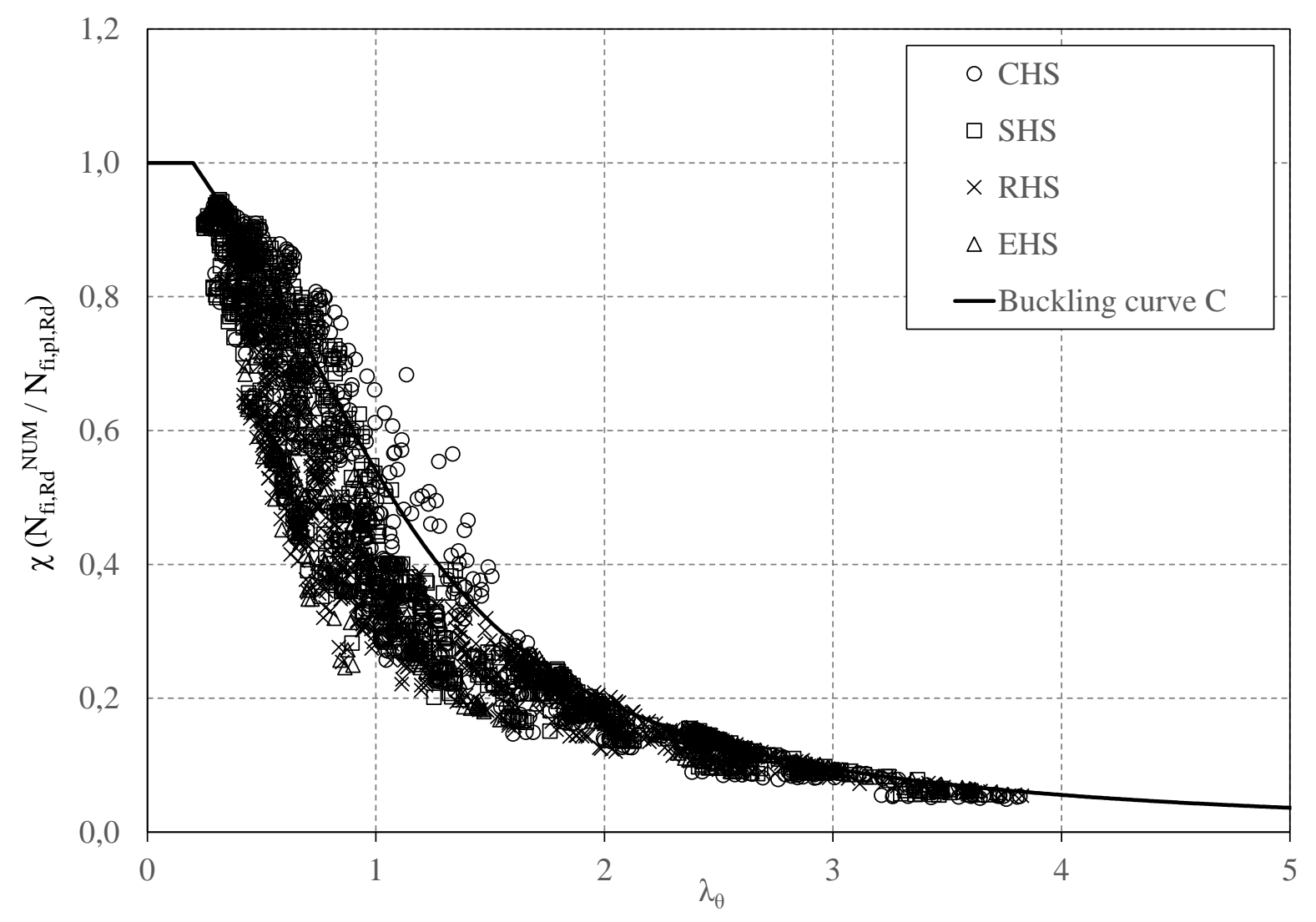

Fig. 5 Results for concentrically loaded columns from the parametric studies. 
a)

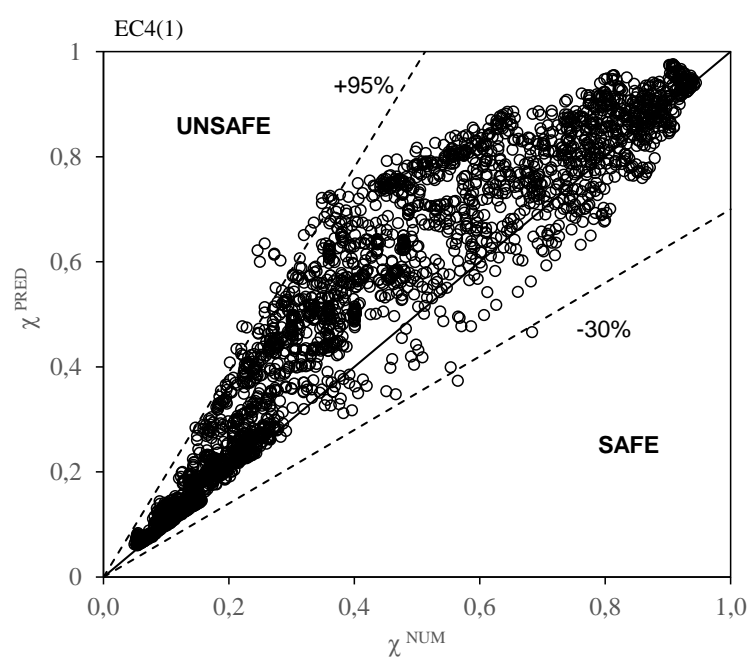

c)

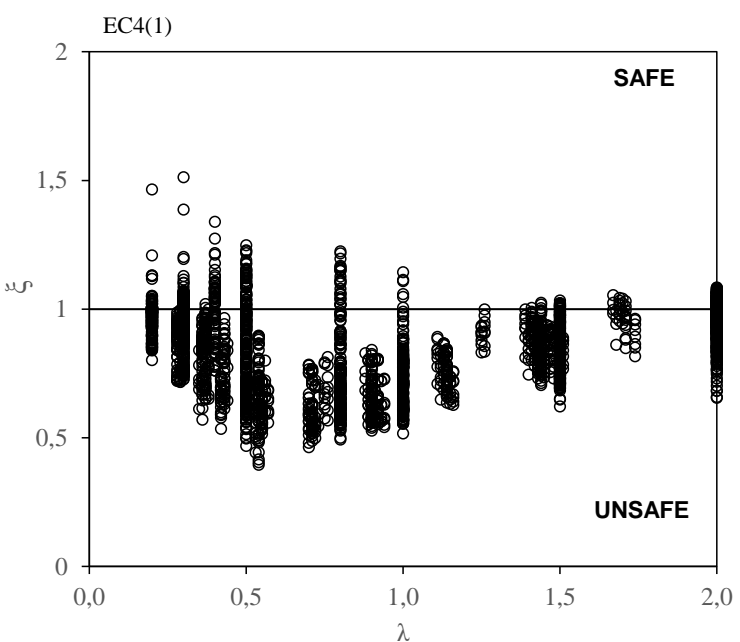

b)

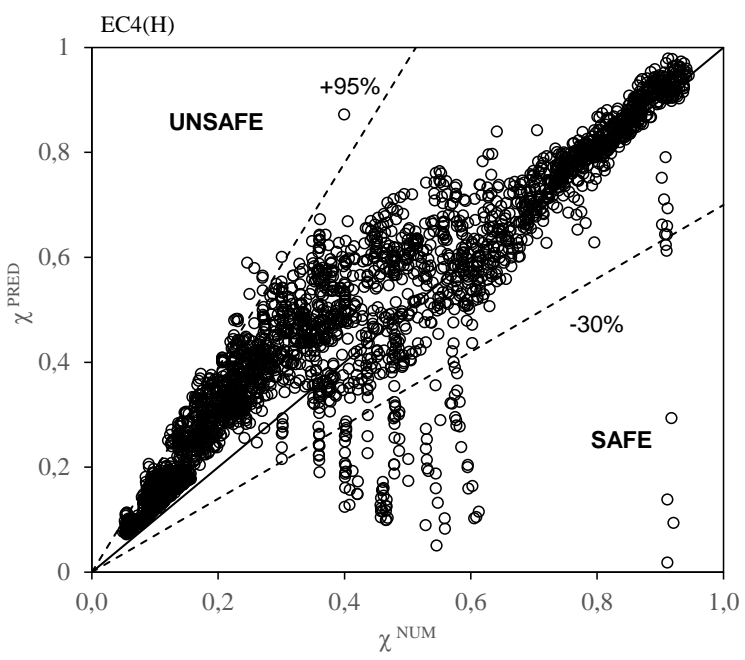

d)

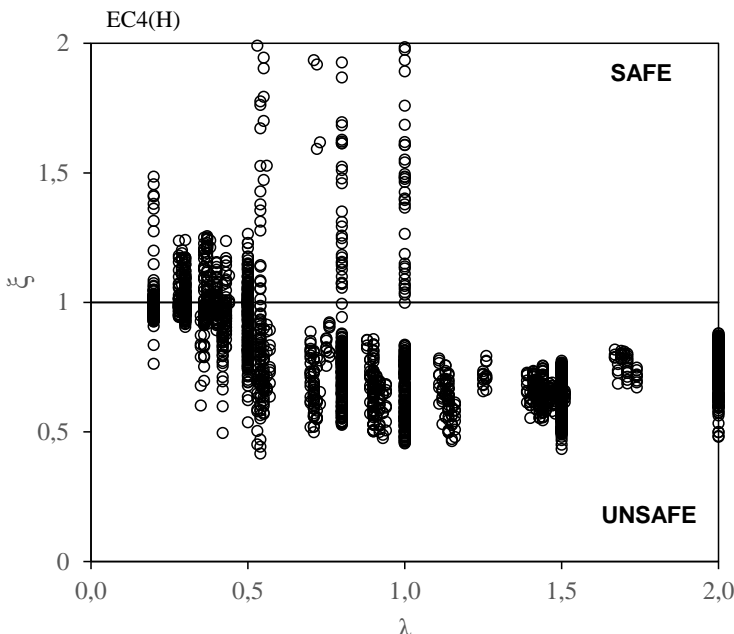

Fig. 6 Comparison between the current methods in EN 1994-1-2 and numerical results (concentrically loaded columns). 
a)

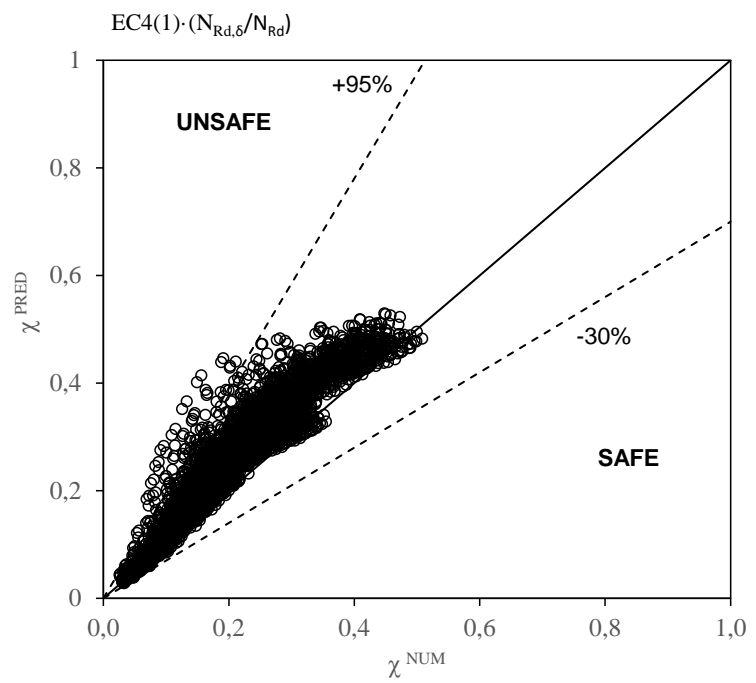

c)

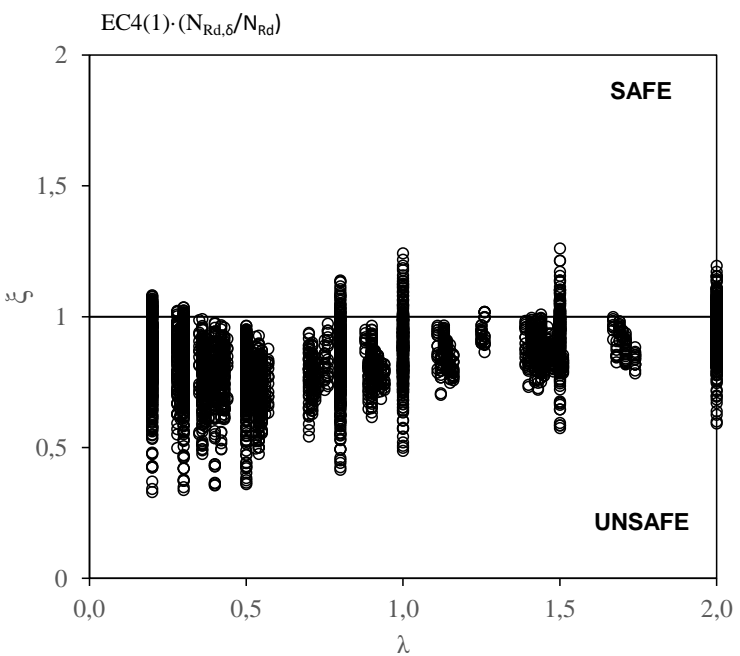

b)

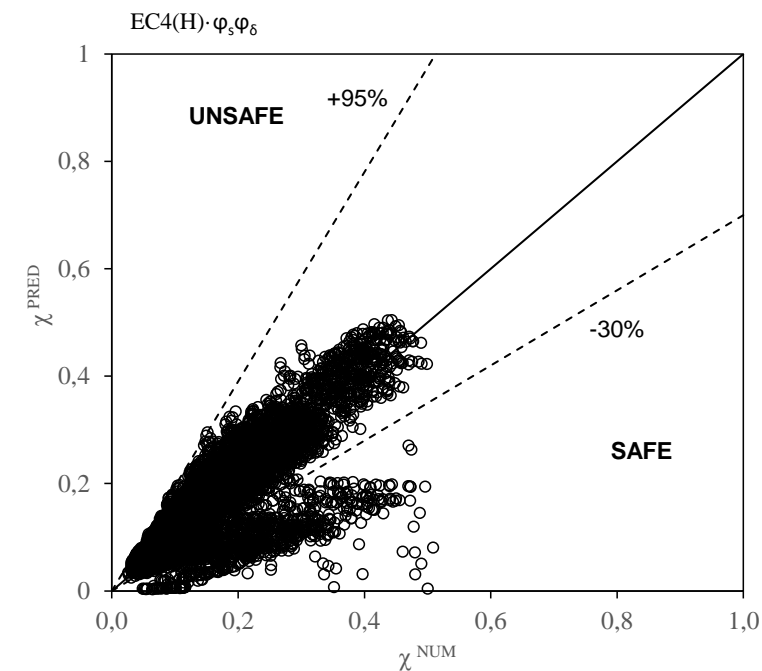

d)

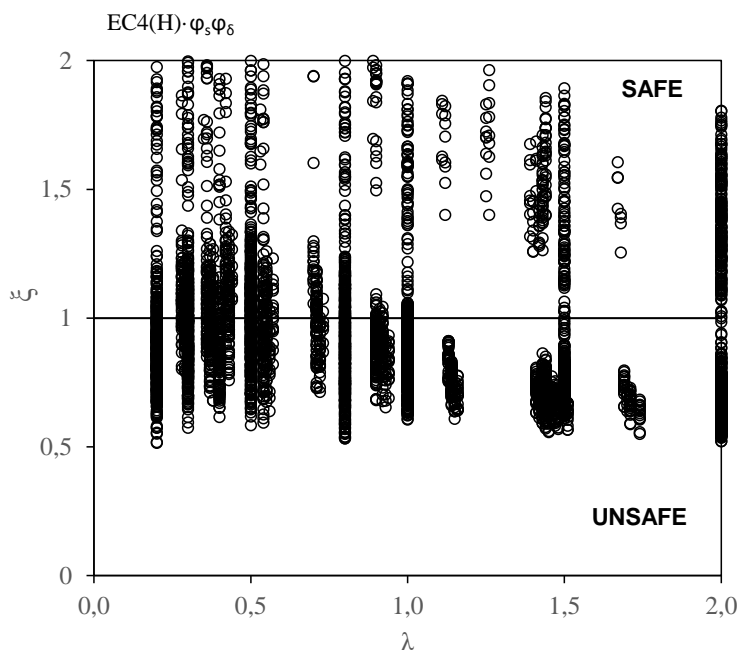

Fig. 7 Comparison between the current methods in EN 1994-1-2 and numerical results (eccentrically loaded columns). 
a)

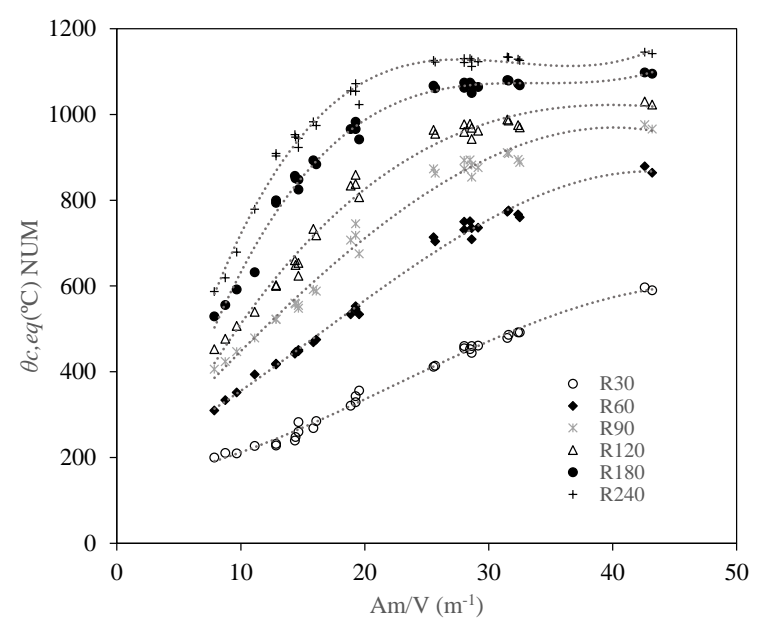

b)

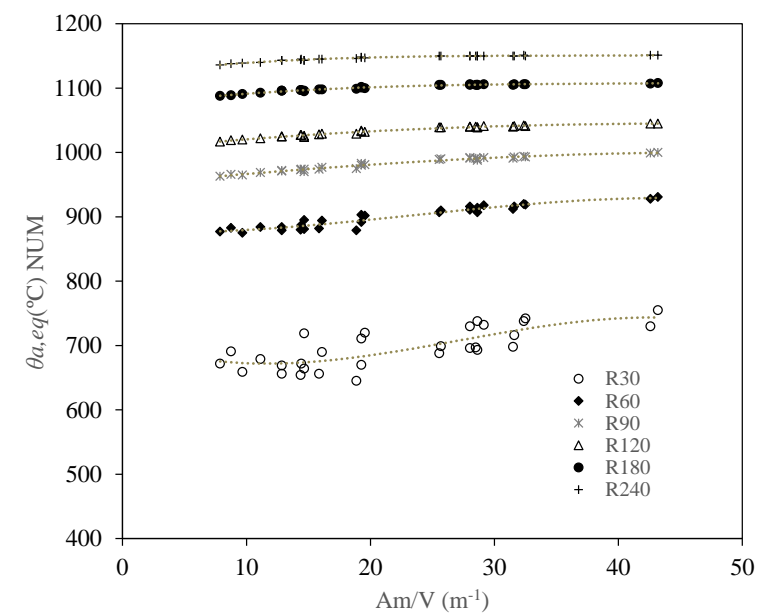

c)

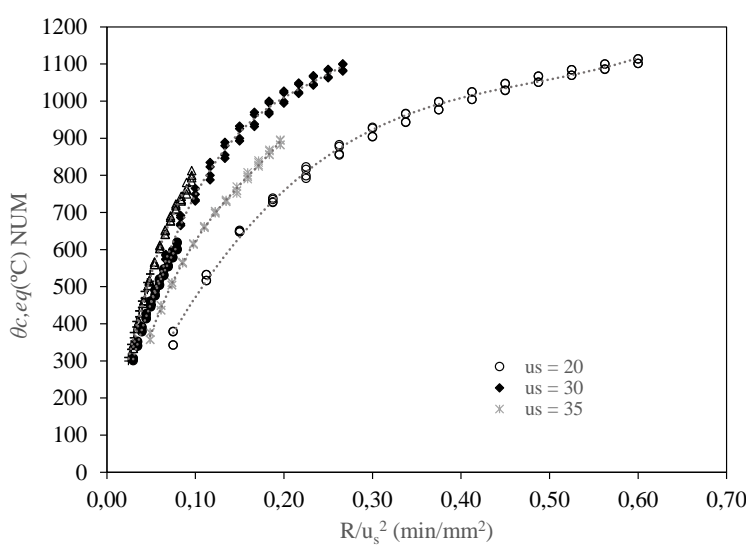

Fig. 8 Evolution of the equivalent temperature: a) concrete core, b) steel tube, c) reinforcing bars. 
Albero V, Espinos A, Romero ML, Hospitaler A, Bihina G, Renaud C. Proposal of a new method in EN1994-1-2 for the fire design of concrete-filled steel tubular columns. Eng. Struct. 2016; 128:237-55. doi: 10.1016/j.engstruct.2016.09.037

a)

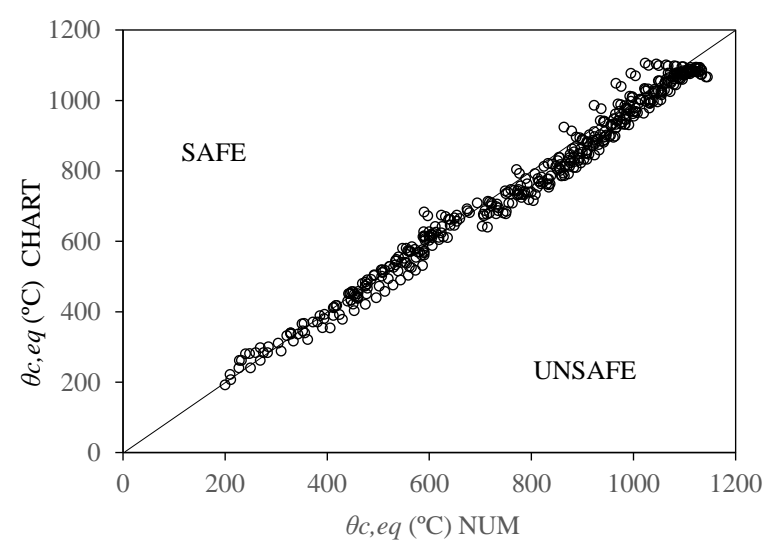

b)

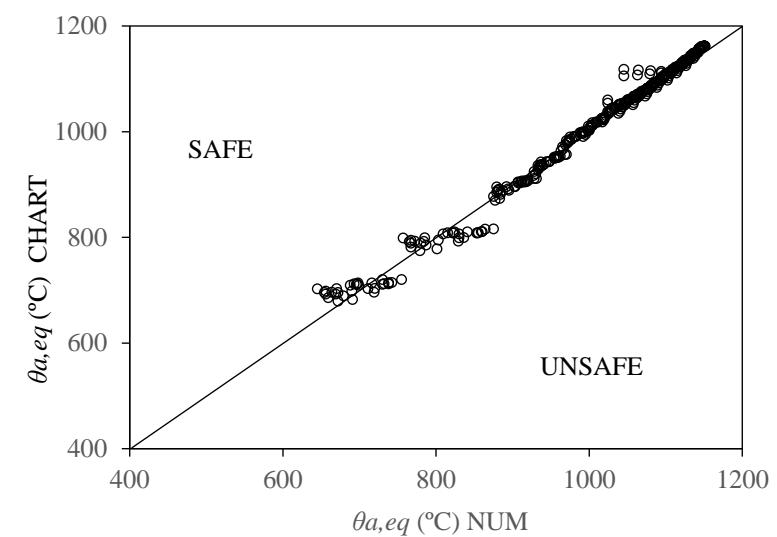

c)

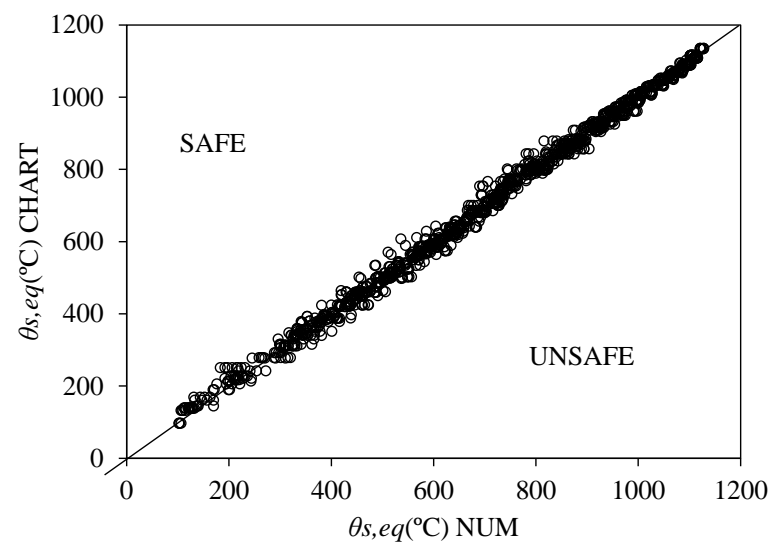

Fig. 9 Comparison between predicted and numerical equivalent temperatures (tabulated data) a) concrete core, b) steel tube, c) reinforcing bars. 


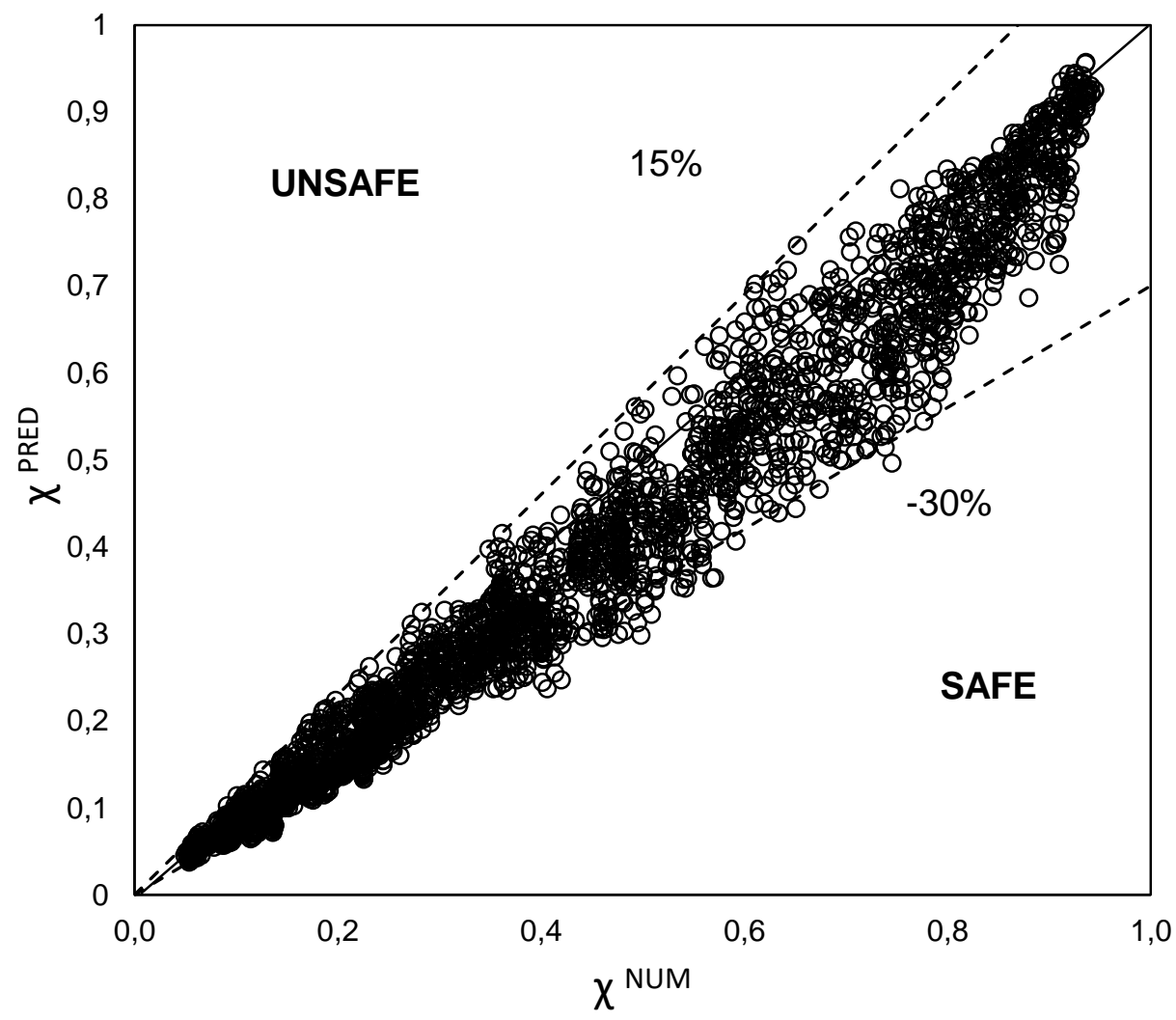

Fig. 10 Comparison between the predictions of the proposed simplified design method and the parametric studies results (concentrically loaded columns). 
Albero V, Espinos A, Romero ML, Hospitaler A, Bihina G, Renaud C. Proposal of a new method in EN1994-1-2 for the fire design of concrete-filled steel tubular columns. Eng. Struct. 2016; 128:237-55. doi: 10.1016/j.engstruct.2016.09.037

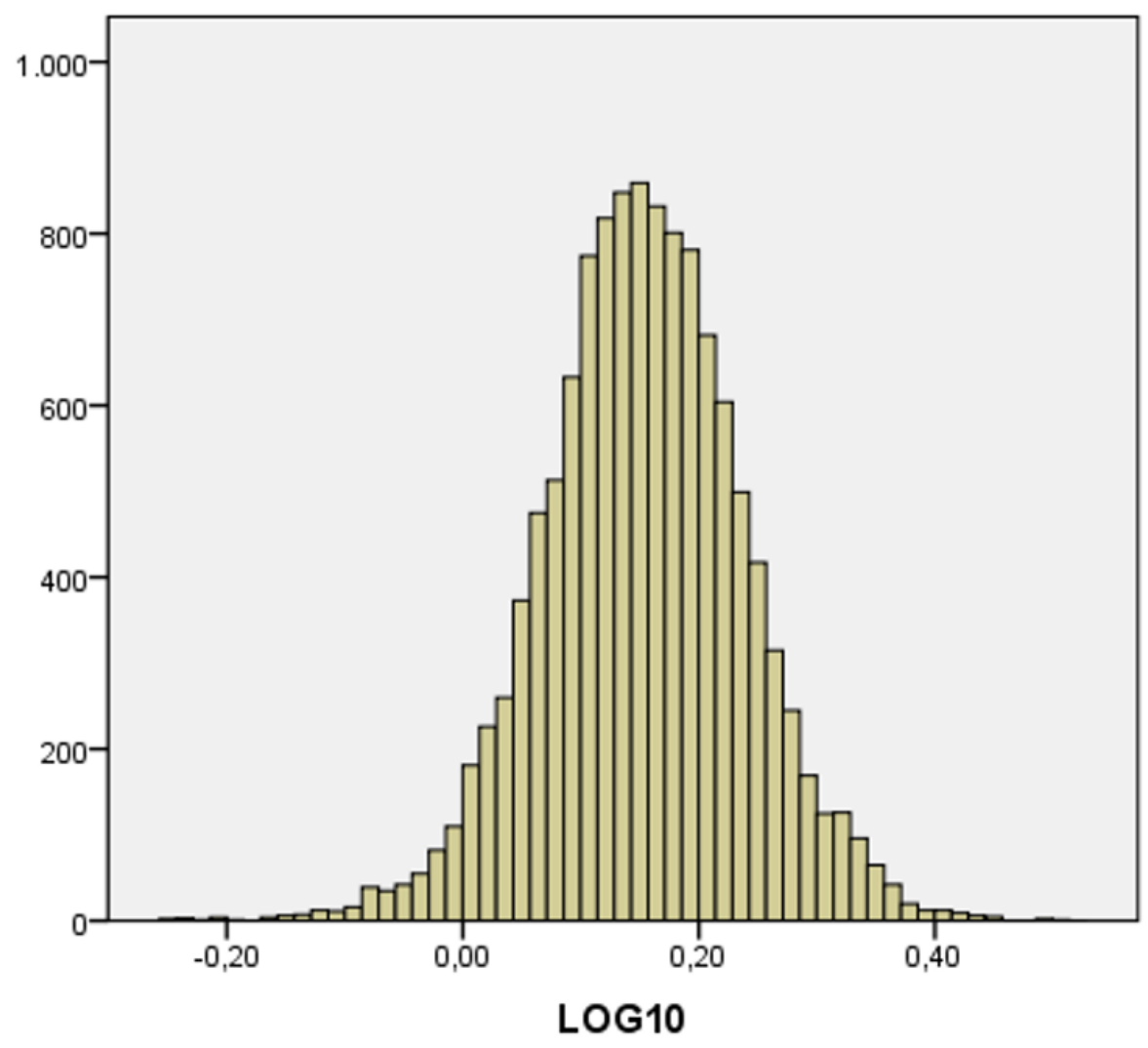

Fig. 11 Normalised frequency histogram for the prediction error obtained with the proposed method for eccentrically loaded specimens. 
a)

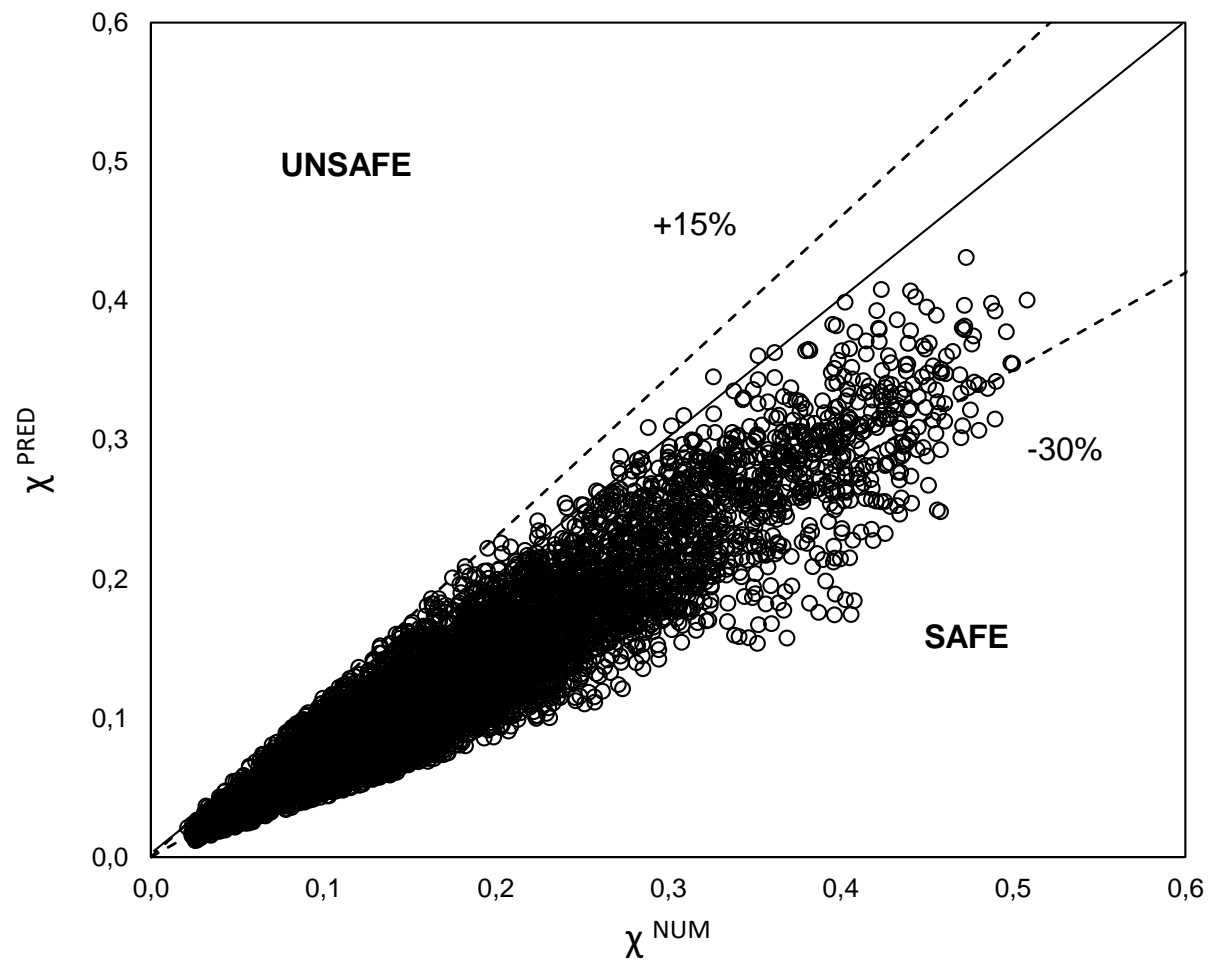

b)

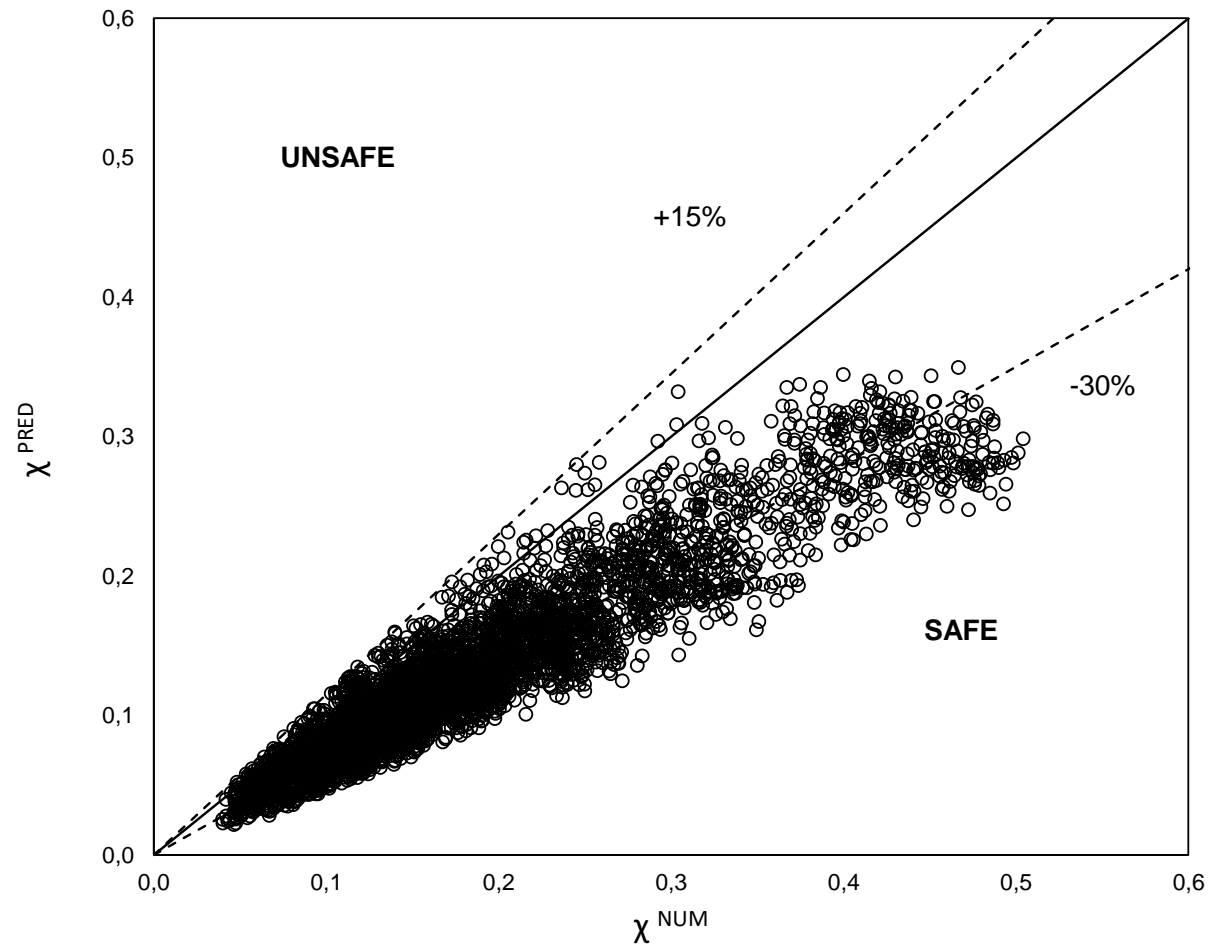

Fig. 12 Comparison between the predictions of the proposed simplified design method and the parametric studies results (eccentrically loaded columns). a) Minor axis. b) Major axis. 


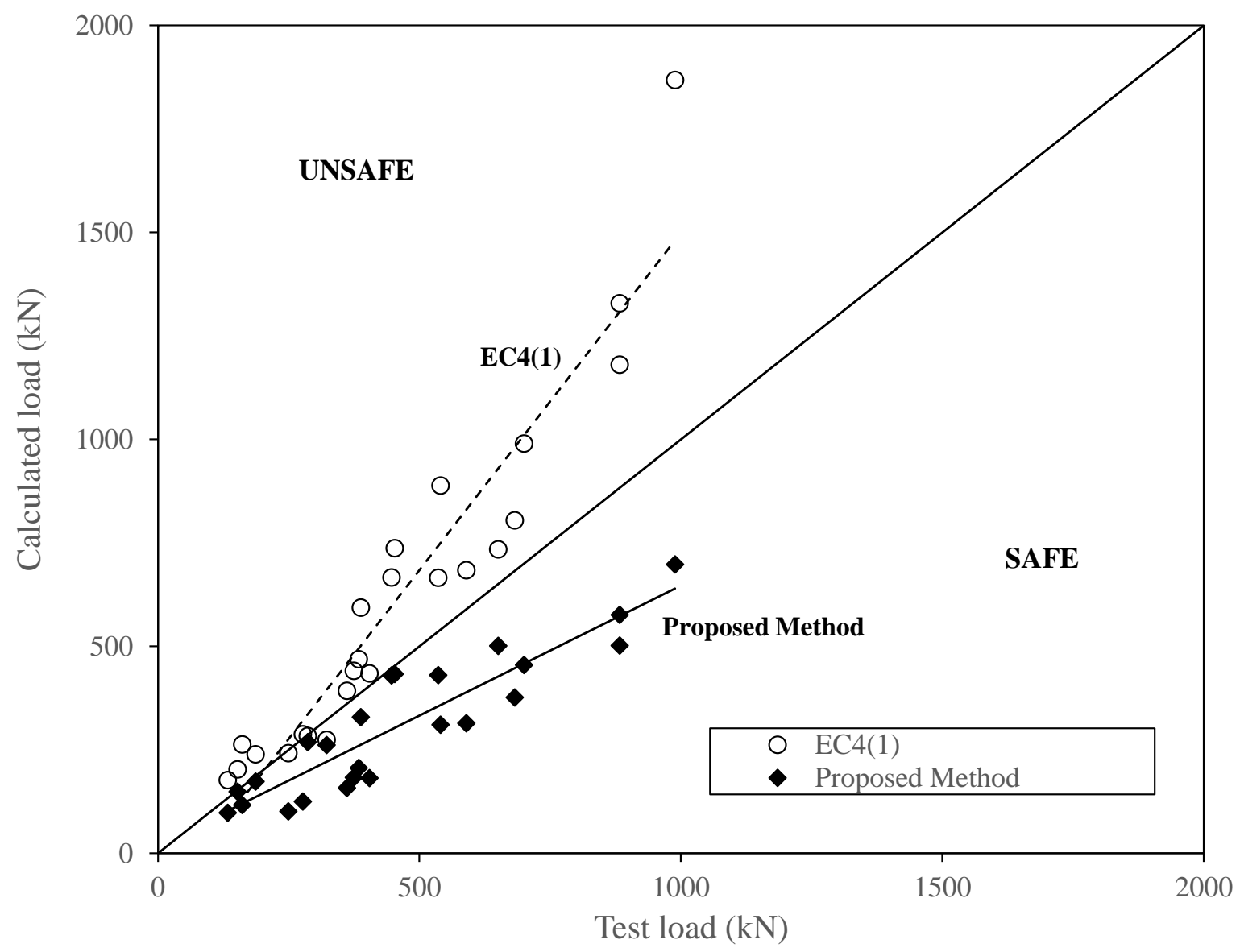

Fig. 13 Comparison of ultimate loads between proposed method, EC4(1) method and tests. 


\section{TABLES}

Table 1 Validation of the numerical models

\begin{tabular}{|c|c|c|c|c|c|}
\hline \multicolumn{2}{|c|}{$\begin{array}{l}\text { Experimental } \\
\text { tests }[31,32]\end{array}$} & \multicolumn{2}{|c|}{ 3D Model } & \multicolumn{2}{|c|}{ 2D Model } \\
\hline & $\mathrm{t}_{\mathrm{TEST}}$ & $\mathrm{t}_{\mathrm{NUM}}$ & $\xi$ & $\mathrm{t}_{\mathrm{NUM}}$ & $\xi$ \\
\hline \multicolumn{6}{|c|}{ CHS } \\
\hline$C 1$ & 26 & 28.2 & 0.92 & 27 & 0.96 \\
\hline$C 2$ & 30 & 32.1 & 0.93 & 31 & 0.97 \\
\hline$C 3$ & 29 & 27.7 & 1.05 & 21 & 1.38 \\
\hline$C 4$ & 72 & 63.2 & 1.14 & 69 & 1.04 \\
\hline$C 5$ & 29 & 28.2 & 1.03 & 35 & 0.83 \\
\hline \multicolumn{6}{|c|}{ SHS } \\
\hline$S 1$ & 26 & 24.3 & 1.07 & 26 & 1.00 \\
\hline$S 2$ & 23 & 32.8 & 0.70 & 31 & 0.74 \\
\hline S3 & 32 & 22.6 & 1.42 & 21 & 1.52 \\
\hline$S 4$ & 54 & 47.6 & 1.13 & 53 & 1.02 \\
\hline S5 & 29 & 24.6 & 1.18 & 34 & 0.85 \\
\hline S6 & 29 & 30.1 & 0.96 & 38 & 0.76 \\
\hline \multicolumn{6}{|c|}{ EHS } \\
\hline E1 & 21 & 26.5 & 0.79 & 23 & 0.91 \\
\hline$E 2$ & 26 & 27.2 & 0.96 & 26 & 1.00 \\
\hline$E 3$ & 28 & 28.8 & 0.97 & 30 & 0.93 \\
\hline E4 & 22 & 25.6 & 0.86 & 23 & 0.96 \\
\hline$E 5$ & 25 & 27.5 & 0.91 & 27 & 0.93 \\
\hline$E 6$ & 26 & 29.7 & 0.88 & 31 & 0.84 \\
\hline$E 7$ & 30 & 29.1 & 1.03 & 27 & 1.11 \\
\hline$E 8$ & 31 & 28.6 & 1.08 & 28 & 1.11 \\
\hline$E 9$ & 30 & 30.3 & 0.99 & 29 & 1.03 \\
\hline E10 & 37 & 36.2 & 1.02 & 40 & 0.93 \\
\hline E11 & 32 & 33.4 & 0.96 & 31 & 1.03 \\
\hline E12 & 38 & 39.6 & 0.96 & 41 & 0.93 \\
\hline \multicolumn{6}{|c|}{ RHS } \\
\hline$R 1$ & 19 & 20.1 & 0.95 & 19 & 1.00 \\
\hline$R 2$ & 23 & 22.7 & 1.01 & 22 & 1.05 \\
\hline$R 3$ & 23 & 25.8 & 0.89 & 25 & 0.92 \\
\hline$R 4$ & 27 & 25.8 & 1.05 & 31 & 0.87 \\
\hline$R 5$ & 24 & 26.0 & 0.92 & 25 & 0.96 \\
\hline R6 & 34 & 28.8 & 1.18 & 34 & 1.00 \\
\hline$R 8$ & 21 & 24.5 & 0.86 & 23 & 0.91 \\
\hline$R 9$ & 22 & 22.3 & 0.99 & 26 & 0.85 \\
\hline$R 10$ & 25 & 30.1 & 0.83 & 30 & 0.83 \\
\hline R11 & 22 & 24.8 & 0.89 & 31 & 0.71 \\
\hline \multirow{2}{*}{111} & & Avg. & 0.99 & Avg. & 0.97 \\
\hline & & $\begin{array}{l}\text { Std. } \\
\text { dev. }\end{array}$ & 0.13 & $\begin{array}{l}\text { Std. } \\
\text { dev. }\end{array}$ & 0.16 \\
\hline
\end{tabular}


Table 2 Combinations of analysis cases for the parametric studies

\begin{tabular}{|c|c|c|c|c|c|c|}
\hline Section shape & \multicolumn{6}{|c|}{ Circular - CHS } \\
\hline$D(\mathrm{~mm})$ & \multicolumn{2}{|c|}{139.7} & \multicolumn{2}{|c|}{273} & \multirow{2}{*}{$\begin{array}{c}457 \\
8 \\
\end{array}$} & 508 \\
\hline$t(\mathrm{~mm})$ & 3 & 12.5 & 5 & 12.5 & & 10 \\
\hline $\bar{\lambda}$ & \multicolumn{4}{|c|}{$0.2-0.3-0.5-0.8-1-1.5-2$} & \multicolumn{2}{|c|}{$0.2-0.3-0.4-0.5-0.8-1-1.5-2$} \\
\hline$u_{s}(\mathrm{~mm})$ & \multicolumn{2}{|c|}{$20-30$} & \multicolumn{2}{|c|}{$35-50$} & \multicolumn{2}{|c|}{$55-70$} \\
\hline$\rho(\%)$ & \multicolumn{6}{|c|}{$0-2.5-5$} \\
\hline$\mu(\%)$ & \multicolumn{6}{|c|}{$15-30-45-60$} \\
\hline$e / D$ & \multicolumn{6}{|c|}{$0-0.25-0.5-0.75-1$} \\
\hline
\end{tabular}

\begin{tabular}{|c|c|c|c|c|c|c|}
\hline \multirow{4}{*}{$\begin{array}{c}\text { Section shape } \\
B(\mathrm{~mm}) \\
t(\mathrm{~mm})\end{array}$} & \multicolumn{6}{|c|}{ Square - SHS } \\
\hline & \multirow{2}{*}{\multicolumn{2}{|c|}{120}} & & & \multirow{3}{*}{\multicolumn{2}{|c|}{$\begin{array}{c}(4400 \text { spec. }) \\
400 \\
12\end{array}$}} \\
\hline & & & \multicolumn{2}{|c|}{200} & & \\
\hline & 4 & 12.5 & 6 & 16 & & \\
\hline $\bar{\lambda}$ & \multicolumn{4}{|c|}{$0.2-0.3-0.5-0.8-1-1.5-2$} & \multicolumn{2}{|c|}{$0.2-0.3-0.4-0.5-0.8-1-1.5-2$} \\
\hline$u_{s}(\mathrm{~mm})$ & & & & 50 & & \\
\hline$\rho(\%)$ & \multicolumn{6}{|c|}{$0-2.5-5$} \\
\hline$\mu(\%)$ & \multicolumn{6}{|c|}{$15-30-45-60$} \\
\hline$e / B$ & \multicolumn{6}{|c|}{$0-0.25-0.5-0.75-1$} \\
\hline
\end{tabular}

\begin{tabular}{|c|c|c|c|c|c|c|c|c|c|}
\hline \multirow{4}{*}{$\begin{array}{c}\text { Section shape } \\
\text { Aspect ratio } \\
H \times B(\mathrm{~mm}) \\
t(\mathrm{~mm})\end{array}$} & \multicolumn{9}{|c|}{ Rectangular - RHS } \\
\hline & \multicolumn{2}{|c|}{$\mathbf{1 . 5}$ (4680 spec) } & \multicolumn{3}{|c|}{2 (2880 spec.) } & \multicolumn{4}{|c|}{3 (576 spec.) } \\
\hline & $150 \times 100$ & $300 \times 200$ & $200 \times 100$ & \multicolumn{2}{|c|}{$400 \times 200$} & \multicolumn{2}{|c|}{$180 \times 60$} & \multicolumn{2}{|c|}{$300 \times 100$} \\
\hline & 10 & 14.2 & $12 * 2$ & 12 & 14.2 & $5 * 2$ & $10 * 2$ & $10^{* 2}$ & $12.5 * 2$ \\
\hline $\begin{array}{c}\bar{\lambda} \\
\text { (major axis) }\end{array}$ & $\begin{array}{c}0.2-0.3- \\
0.5-0.8-1 \\
-1.2-(2) * 1 \\
\end{array}$ & $\begin{array}{c}0.2-0.3- \\
0.5-0.8-1 \\
-(2) * 1\end{array}$ & \multicolumn{3}{|c|}{$0.2-0.3-0.5-0.8-(2) * 1$} & \multicolumn{4}{|c|}{$0.2-0.3-0.5-(2) * 1$} \\
\hline$u_{s}(\mathrm{~mm})$ & $20-30$ & $35-50$ & $20-30$ & & & 15 & & & -30 \\
\hline$\rho(\%)$ & \multicolumn{9}{|c|}{$0-2.5-5$} \\
\hline$\mu(\%)$ & \multicolumn{9}{|c|}{$15-30-50-70$} \\
\hline$e / B($ or $e / H)$ & \multicolumn{9}{|c|}{$0-0.25-0.5-0.75-1$} \\
\hline axis & \multicolumn{9}{|c|}{ major axis - minor axis } \\
\hline
\end{tabular}

\begin{tabular}{|c|c|c|c|c|}
\hline \multirow{2}{*}{ Section shape } & \multicolumn{4}{|c|}{ Elliptical - EHS } \\
(3600 spec.)
\end{tabular}

(*1): Relative slenderness in minor axis

(*2): Reinforcement not possible because of minimum rebar spacing requirements from EN 1992-1-1 Section 8.2 
Table 3 Selection chart for the equivalent temperature of concrete core $\theta_{c, e q}\left({ }^{\circ} C\right)$ and steel tube $\theta_{a, e q}\left({ }^{\circ} \mathrm{C}\right)$

\begin{tabular}{|c|c|c|c|c|c|c|c|c|c|c|c|c|c|}
\cline { 3 - 12 } \multicolumn{2}{c|}{} & \multicolumn{2}{c|}{ R30 } & \multicolumn{2}{c|}{ R60 } & \multicolumn{2}{c|}{ R90 } & \multicolumn{2}{c|}{ R120 } & \multicolumn{2}{c|}{ R180 } & \multicolumn{2}{c|}{ R240 } \\
\cline { 3 - 7 } & $\theta_{c, e q}$ & $\theta_{a, e q}$ & $\theta_{c, e q}$ & $\theta_{a, e q}$ & $\theta_{c, e q}$ & $\theta_{a, e q}$ & $\theta_{c, e q}$ & $\theta_{a, e q}$ & $\theta_{c, e q}$ & $\theta_{a, e q}$ & $\theta_{c, e q}$ & $\theta_{a, e q}$ \\
\hline \multirow{4}{*}{} & $\mathbf{5}$ & 146 & 669 & 197 & 858 & 228 & 951 & 248 & 1005 & 274 & 1070 & 293 & 1125 \\
& $\mathbf{1 0}$ & 227 & 687 & 356 & 879 & 447 & 973 & 518 & 1028 & 625 & 1094 & 708 & 1149 \\
& $\mathbf{1 5}$ & 288 & 697 & 465 & 890 & 590 & 984 & 686 & 1039 & 827 & 1105 & 927 & 1158 \\
$\boldsymbol{A}_{\boldsymbol{m}} / \boldsymbol{V}$ & $\mathbf{2 0}$ & 345 & 704 & 553 & 897 & 696 & 992 & 803 & 1046 & 950 & 1110 & 1042 & 1162 \\
$\left(\mathrm{~m}^{-1}\right)$ & $\mathbf{2 5}$ & 404 & 709 & 632 & 903 & 783 & 996 & 891 & 1050 & 1024 & 1112 & 1091 & 1162 \\
& $\mathbf{3 0}$ & 469 & 713 & 708 & 906 & 860 & 999 & 960 & 1052 & 1067 & 1113 & 1095 & 1162 \\
& $\mathbf{3 5}$ & 541 & 716 & 786 & 909 & 932 & 1001 & 1020 & 1053 & 1089 & 1113 & 1062 & 1162 \\
& $\mathbf{4 0}$ & 624 & 719 & 868 & 911 & 1002 & 1002 & 1054 & 1054 & 1096 & 1113 & 1062 & 1162 \\
& $\mathbf{4 5}$ & 717 & 721 & 912 & 912 & 1003 & 1003 & 1054 & 1054 & 1096 & 1113 & 1062 & 1162 \\
\hline
\end{tabular}


Table 4 Coefficients for the equivalent temperature of the reinforcement $\theta_{s, e q}\left({ }^{\circ} \mathrm{C}\right)$

\begin{tabular}{|c|c|c|c|c|c|}
\hline & $\begin{array}{c}\boldsymbol{u}_{\boldsymbol{s}} \\
(\mathbf{m m})\end{array}$ & $\boldsymbol{\chi}_{\mathbf{3}}$ & $\boldsymbol{\chi}_{\mathbf{2}}$ & $\boldsymbol{\chi}_{\mathbf{1}}$ & $\boldsymbol{\chi}_{\mathbf{0}}$ \\
\hline \multirow{4}{*}{ CHS } & 20 & 7236.5 & -10458 & 5497.6 & 19.38 \\
\cline { 2 - 6 } & 30 & 58714 & -41328 & 10910 & 11.179 \\
\cline { 2 - 6 } & 35 & 0 & -12732 & 6518 & 91.208 \\
\cline { 2 - 6 } & 50 & 0 & -55639 & 13768 & -19.897 \\
\cline { 2 - 6 } & 55 & 0 & -43201 & 10790 & 24.229 \\
\cline { 2 - 6 } & 70 & 0 & 0 & 8858 & 96.676 \\
\hline \multirow{5}{*}{ SHS } & 20 & 8151.3 & -11323 & 5595.4 & 93.392 \\
\cline { 2 - 6 } & 30 & 85460 & -54898 & 12825 & -22.081 \\
\cline { 2 - 6 } & 35 & 0 & -18802 & 8222.9 & 116.34 \\
\cline { 2 - 6 } & 50 & 0 & -67134 & 15912 & 16.125 \\
\cline { 2 - 6 } & 55 & 0 & -78597 & 14878 & -43.033 \\
\cline { 2 - 6 } & 70 & 0 & 0 & 11922 & 23.258 \\
\hline \multirow{4}{*}{ RHS } & 20 & 7863.2 & -10978 & 5465.2 & 108.38 \\
\cline { 2 - 6 } & 30 & 82790 & -53604 & 12626 & -8.4515 \\
\cline { 2 - 6 } & 35 & 0 & -20109 & 8575.4 & 53.012 \\
\hline \multirow{4}{*}{ EHS } & 50 & 0 & -79340 & 17108 & -54.085 \\
\cline { 2 - 6 } & 30 & 79543 & -51871 & 12481 & -45.483 \\
\cline { 2 - 6 } & 50 & 304952 & -117159 & 18180 & -111.73 \\
\cline { 2 - 6 } & 65 & 0 & -100810 & 18531 & -35.745 \\
\hline
\end{tabular}


Table 5 Selection chart for the equivalent temperature of the reinforcement $\theta_{s, e q}\left({ }^{\circ} C\right)$

\begin{tabular}{|c|c|c|c|c|c|c|c|c|c|c|c|c|c|}
\hline \multicolumn{14}{|c|}{$\theta_{s, e q}\left({ }^{\circ} \mathrm{C}\right)$} \\
\hline \multicolumn{7}{|c|}{ CHS } & \multicolumn{7}{|c|}{ SHS } \\
\hline$\underset{(\mathrm{mm})}{\boldsymbol{u}_{\boldsymbol{s}}}$ & R3O & $R 60$ & $R 90$ & $R 120$ & R180 & $R 240$ & $\underset{(m m)}{\boldsymbol{U}_{\boldsymbol{s}}}$ & $R 30$ & $R 60$ & $R 90$ & $R 120$ & R180 & $R 240$ \\
\hline 20 & 376 & 634 & 810 & & 5 & 117 & 20 & 453 & 706 & 872 & 4 & 062 & 1136 \\
\hline 30 & 332 & 73 & 748 & 8 & 1010 & 1096 & 30 & 348 & 615 & 797 & 15 & 031 & 1115 \\
\hline 35 & 244 & 380 & 502 & 608 & 775 & 880 & 35 & 307 & 474 & 619 & 742 & 919 & 1006 \\
\hline 50 & 138 & 279 & 404 & 51 & 68 & 790 & 50 & 198 & 360 & 502 & 626 & 814 & 925 \\
\hline 55 & 127 & 222 & 308 & 385 & 514 & 609 & 55 & 97 & 222 & 331 & 424 & 565 & 643 \\
\hline 70 & 127 & 06 & 260 & 314 & 423 & 531 & 70 & 97 & 170 & 243 & 316 & 462 & 608 \\
\hline \multicolumn{7}{|c|}{ EHS } & \multicolumn{7}{|c|}{ RHS } \\
\hline$\underset{(m m)}{\boldsymbol{u}_{\boldsymbol{s}}}$ & R3O & $R 60$ & $R 90$ & $R 120$ & $R 180$ & $R 240$ & 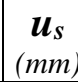 & R3O & $R 60$ & $R 90$ & $R 120$ & $R 180$ & $R 240$ \\
\hline 30 & 31 & 580 & 7 & 8 & \begin{tabular}{|l|l}
1013 \\
\end{tabular} & 110 & 20 & 460 & 708 & 872 & 9/3 & \begin{tabular}{|l|l}
1062 \\
\end{tabular} & 1134 \\
\hline 40 & 190 & 422 & 595 & 72 & 885 & 1009 & 30 & 356 & 620 & 801 & 919 & 1035 & 1117 \\
\hline 55 & 139 & 293 & 427 & 541 & 710 & 800 & 35 & 251 & 425 & 575 & 701 & 879 & 962 \\
\hline 65 & 72 & 214 & 340 & 451 & 624 & 733 & 50 & 140 & 311 & 459 & 585 & 767 & 858 \\
\hline
\end{tabular}


Table 6 Proposed reduction coefficients for the steel tube

\begin{tabular}{|c|c|}
\hline \multicolumn{2}{|l|}{ CHS } \\
\hline$l_{\theta} / D \leq 12$ & $l_{\theta} / D>12$ \\
\hline$\varphi_{a, \theta, 1}=6.05-1.16 \cdot\left(A_{m} / V\right)^{0.417}$ & $\varphi_{a, \theta, 1}=0.2$ \\
\hline$\varphi_{a, \theta, 2}=0.55+0.082 \cdot\left(l_{\theta} / D\right)^{0.979}$ & $\varphi_{a, \theta, 2}=-4262+4253 \cdot\left(l_{\theta} / D\right)^{9.03 \cdot 10^{-4}}$ \\
\hline$\varphi_{a, \theta, 3}=566.37-565.25 \cdot(D / t)^{2.21 \cdot 10^{-4}}$ & $\varphi_{a, \theta, 3}=0.5375+7.5 \cdot 10^{-3} \cdot(D / t)$ \\
\hline$\varphi_{a, \theta, 4}=0.116+8.84 \cdot 10^{-12} \cdot(R)^{4.285}$ & $\varphi_{a, \theta, 4}=2.66-0.44 \cdot(R)^{0.28}$ \\
\hline \multicolumn{2}{|l|}{ SHS } \\
\hline$l_{\theta} / B \leq 12$ & $l_{\theta} / B>12$ \\
\hline$\varphi_{a, \theta, 1}=16.1-15.2 \cdot\left(A_{m} / V\right)^{8.43 \cdot 10^{-3}}$ & $\varphi_{a, \theta, 1}=3.08+0.1 \cdot\left(A_{m} / V\right)^{-0.1412}$ \\
\hline$\varphi_{a, \theta, 2}=-103+103 \cdot\left(l_{\theta} / B\right)^{2.43 \cdot 10^{-3}}$ & $\varphi_{a, \theta, 2}=-3.526+3.1 \cdot(L / B)^{5.88 \cdot 10^{-2}}$ \\
\hline$\varphi_{a, \theta, 3}=0.381+0.043 \cdot(B / t)^{0.834}$ & $\varphi_{a, \theta, 3}=1.255-2.2 \cdot 10^{-2} \cdot(B / t)$ \\
\hline$\varphi_{a, \theta, 4}=0.58+7.3 \cdot 10^{-18} \cdot(R)^{6.974}$ & $\varphi_{a, \theta, 4}=0.67-2.85 \cdot 10^{-3} \cdot(R)^{1.084}$ \\
\hline \multicolumn{2}{|l|}{ RHS } \\
\hline$l_{\theta} / B \leq 30$ & $l_{\theta} / B>30$ \\
\hline$\varphi_{a, \theta, 1}=-2.218+2.243 \cdot\left(A_{m} / V\right)^{1.609 \cdot 10^{-2}}$ & $\varphi_{a, \theta, 1}=-84.4+84.9 \cdot(A / V)^{5.75 \cdot 10^{-4}}$ \\
\hline$\varphi_{a, \theta, 2}=0.253+1.296310^{-6} \cdot\left(l_{\theta} / B\right)^{3.9659}$ & $\varphi_{a, \theta, 2}=-0.482+0.187 \cdot\left(l_{\theta} / B\right)^{0.587}$ \\
\hline$\varphi_{a, \theta, 3}=200-195.8 \cdot(B / t)^{4.046 \cdot 10^{-3}}$ & $\varphi_{a, \theta, 3}=0.925-5.75 \cdot 10^{-2} \cdot(B / t)^{0.5186}$ \\
\hline$\varphi_{a, \theta, 4}=1$ & $\varphi_{a, \theta, 4}=1$ \\
\hline \multicolumn{2}{|l|}{ EHS } \\
\hline$l_{\theta} / B \leq 23$ & $l_{\theta} / B>23$ \\
\hline$\varphi_{a, \theta, 1}=0.298+5.07 \cdot 10^{-7} \cdot\left(A_{m} / V\right)^{3.373}$ & $\varphi_{a, \theta, 1}=-31.9+34.4 \cdot\left(A_{m} / V\right)^{0.008}$ \\
\hline$\varphi_{a, \theta, 2}=0.5872+1 \cdot 10^{-18} \cdot\left(l_{\theta} / B\right)^{13.275}$ & $\varphi_{a, \theta, 2}=-0.224+0.08035 \cdot\left(l_{\theta} / B\right)^{0.7161}$ \\
\hline$\varphi_{a, \theta, 3}=714.27-712.69 \cdot(B / t)^{3.97 \cdot 10^{-4}}$ & $\varphi_{a, \theta, 3}=0.26-1.59 \cdot 10^{-3} \cdot(B / t)^{1.2}$ \\
\hline$\varphi_{a, \theta, 4}=1$ & $\varphi_{a, \theta, 4}=1$ \\
\hline
\end{tabular}


Table 7 Proposed reduction coefficients for the reinforcement

\begin{tabular}{|c|c|}
\hline \multicolumn{2}{|l|}{ CHS } \\
\hline$\rho \leq 2.5 \%$ & $2.5 \% \leq \rho \leq 5 \%$ \\
\hline$\varphi_{\mathrm{s}, \theta, 1}=0.23+0.018 \cdot\left(A_{m} / V\right)$ & $\varphi_{\mathrm{s}, \theta, 1}=0.57+0.017\left(A_{m} / V\right)$ \\
\hline$\varphi_{a, \theta, 2}=0.8-0.001 \cdot(R)$ & $\varphi_{s, \theta, 2}=0.83-0.001 \cdot(R)$ \\
\hline \multicolumn{2}{|l|}{ SHS } \\
\hline$\rho \leq 2.5 \%$ & $2.5 \% \leq \rho \leq 5 \%$ \\
\hline$\varphi_{a, \theta, 1}=0.76+0.008 \cdot\left(A_{m} / V\right)$ & $\varphi_{a, \theta, 1}=0.76+0.008 \cdot\left(A_{m} / V\right)$ \\
\hline$\varphi_{a, \theta, 2}=0.7+0.0005 \cdot(R)$ & $\varphi_{a, \theta, 2}=0.83-0.0005 \cdot(R)$ \\
\hline \multicolumn{2}{|l|}{ RHS } \\
\hline$\rho \leq 2.5 \%$ & $2.5 \% \leq \rho \leq 5 \%$ \\
\hline$\varphi_{a, \theta, 1}=0.85$ & $\varphi_{a, \theta, 1}=0.7$ \\
\hline$\varphi_{a, \theta, 2}=1$ & $\varphi_{a, \theta, 2}=1$ \\
\hline \multicolumn{2}{|l|}{ EHS } \\
\hline$\rho \leq 2.5 \%$ & $2.5 \% \leq \rho \leq 5 \%$ \\
\hline$\varphi_{a, \theta, 1}=0.95$ & $\varphi_{a, \theta, 1}=0.95$ \\
\hline$\varphi_{a, \theta, 2}=1$ & $\varphi_{a, \theta, 2}=1$ \\
\hline
\end{tabular}


Albero V, Espinos A, Romero ML, Hospitaler A, Bihina G, Renaud C. Proposal of a new method in EN1994-1-2 for the fire design of concrete-filled steel tubular columns. Eng. Struct. 2016; 128:237-55. doi: 10.1016/j.engstruct.2016.09.037

Table 8 Assessment of the accuracy of the proposed simplified design method

\begin{tabular}{|c|c|c|c|c|}
\hline \multirow{2}{*}{$\begin{array}{c}\text { Accuracy } \\
\text { parameters }\end{array}$} & \multirow{2}{*}{ Axially loaded } & \multicolumn{2}{|c|}{ Eccentrically loaded } & HGF [36] \\
\cline { 3 - 5 } & 1.2 & 1.45 & major axis & \\
\hline Avg. error & 0.16 & 0.27 & 1.42 & $>1$ \\
\hline Std. dev. & $14.9 \%$ & $14.7 \%$ & 0.24 & - \\
\hline Max. unsafe dev. & $8.0 \%$ & $2.4 \%$ & $14.5 \%$ & $<15 \%$ \\
\hline $\begin{array}{c}\text { Num. unsafe } \\
\text { results }\end{array}$ & $47.1 \%$ & $57.3 \%$ & $3.1 \%$ & $<20 \%$ \\
\hline Max. safe dev. & & $57.8 \%$ & - \\
\hline
\end{tabular}


Table 9 Comparison between the simplified design method predictions and experimental results

\begin{tabular}{|c|c|c|c|c|c|c|}
\hline \multirow{2}{*}{ Id. } & \multicolumn{2}{|c|}{ Tests $[\mathbf{3 1 , 3 2 ]}$} & \multicolumn{2}{|c|}{ EC4 (1) } & \multicolumn{2}{c|}{$\begin{array}{c}\text { Proposed } \\
\text { Method }\end{array}$} \\
\cline { 2 - 7 } & $\begin{array}{c}\mathrm{t}_{\text {TEST }} \\
(\mathrm{min})\end{array}$ & $\begin{array}{c}\mathrm{N}_{\text {TEST }} \\
(\mathrm{kN})\end{array}$ & $\begin{array}{c}\mathrm{N}_{\text {PRED }} \\
(\mathrm{kN})\end{array}$ & $\xi$ & $\begin{array}{c}\mathrm{N}_{\text {PRED }} \\
(\mathrm{kN})\end{array}$ & $\xi$ \\
\hline$C 1$ & 26 & 186.7 & 238.9 & 0.78 & 173.5 & 1.08 \\
\hline$C 2$ & 30 & 387.5 & 593.5 & 0.65 & 329.1 & 1.18 \\
\hline$C 3$ & 29 & 535.6 & 665.2 & 0.81 & 430.6 & 1.24 \\
\hline$C 4$ & 72 & 882.9 & 1180.4 & 0.75 & 576.0 & 1.53 \\
\hline$C 5$ & 29 & 152.4 & 203.0 & 0.75 & 148.8 & 1.02 \\
\hline$S 1$ & 26 & 161.1 & 262.8 & 0.61 & 116.3 & 1.38 \\
\hline$S 2$ & 23 & 446.5 & 666.2 & 0.67 & 429.6 & 1.04 \\
\hline$S 3$ & 32 & 404.3 & 434.5 & 0.93 & 181.5 & 2.23 \\
\hline$S 4$ & 54 & 882.9 & 1328.7 & 0.66 & 501.4 & 1.76 \\
\hline$S 5$ & 29 & 133.2 & 176.7 & 0.75 & 97.6 & 1.37 \\
\hline$S 6$ & 29 & 452.6 & 736.7 & 0.61 & 432.8 & 1.05 \\
\hline$E 7$ & 30 & 589.8 & 683.7 & 0.86 & 314.2 & 1.88 \\
\hline$E 8$ & 31 & 681.9 & 804.1 & 0.85 & 376.4 & 1.81 \\
\hline$E 9$ & 30 & 361.0 & 392.6 & 0.92 & 158.1 & 2.28 \\
\hline$E 10$ & 37 & 249.4 & 242.1 & 1.03 & 100.9 & 2.47 \\
\hline$E 12$ & 38 & 286.5 & 283.5 & 1.01 & 268.6 & 1.07 \\
\hline$R 1$ & 19 & 650.8 & 734.4 & 0.89 & 500.9 & 1.30 \\
\hline$R 2$ & 23 & 699.8 & 989.3 & 0.71 & 454.8 & 1.54 \\
\hline$R 3$ & 23 & 374.7 & 441.0 & 0.85 & 183.0 & 2.05 \\
\hline$R 4$ & 27 & 276.9 & 287.3 & 0.96 & 125.0 & 2.22 \\
\hline$R 6$ & 34 & 322.1 & 274.2 & 1.17 & 261.2 & 1.23 \\
\hline$R 8$ & 21 & 988.8 & 1867.9 & 0.53 & 697.7 & 1.42 \\
\hline$R 9$ & 22 & 540.1 & 888.5 & 0.61 & 310.8 & 1.74 \\
\hline$R 10$ & 25 & 383.9 & 468.4 & 0.82 & 206.2 & 1.86 \\
\hline & & & $A v g$. & $\mathbf{0 . 8 0}$ & Avg. & $\mathbf{1 . 5 7}$ \\
\cline { 5 - 7 } & & & Std. dev. & $\mathbf{0 . 1 6}$ & Std. dev. & $\mathbf{0 . 4 5}$ \\
\hline & & & & & & \\
\hline
\end{tabular}

